Published in final edited form as:

Nat Mater. 2016 June ; 15(6): 669-678. doi:10.1038/nmat4570.

\title{
Biodegradable scaffold with built-in vasculature for organ-on-a- chip engineering and direct surgical anastomosis
}

\author{
Boyang Zhang ${ }^{1,2}$, Miles Montgomery ${ }^{1,2}$, M. Dean Chamberlain ${ }^{2}$, Shinichiro Ogawa ${ }^{7}$, \\ Anastasia Korolj ${ }^{1}$, Aric Pahnke ${ }^{1,2}$, Laura A. Wells ${ }^{2}$, Stéphane Massé ${ }^{5}$, Jihye Kim ${ }^{3}$, Lewis \\ Reis $^{2}$, Abdulah Momen ${ }^{4}$, Sara S. Nunes ${ }^{4}$, Aaron Wheeler ${ }^{1,3}$, Kumaraswamy Nanthakumar $^{5}$, \\ Gordon Keller ${ }^{7}$, Michael V. Sefton ${ }^{1,2}$, and Milica Radisic ${ }^{1,2,6,{ }^{*}}$ \\ ${ }^{1}$ Department of Chemical Engineering, University of Toronto, Toronto, Ontario, Canada. \\ ${ }^{2}$ Institute of Biomaterials and Biomedical Engineering, University of Toronto, Toronto, Ontario, \\ Canada. \\ ${ }^{3}$ Department of Chemistry, University of Toronto, Toronto, Ontario, Canada. \\ ${ }^{4}$ Toronto General Research Institute, University Health Network, Toronto, Ontario, Canada. \\ ${ }^{5}$ The Toby Hull Cardiac Fibrillation Management Laboratory, Toronto General Hospital, Toronto, \\ Ontario, Canada. \\ ${ }^{6}$ The Heart and Stroke/Richard Lewar Centre of Excellence, Toronto, Ontario, Canada. \\ ${ }^{7}$ McEwen Center for Regenerative Medicine, Toronto, Ontario, Canada
}

\begin{abstract}
We report the fabrication of a scaffold (hereafter referred to as AngioChip) that supports the assembly of parenchymal cells on a mechanically tunable matrix surrounding a perfusable, branched, three-dimensional microchannel network coated with endothelial cells. The design of AngioChip decouples the material choices for the engineered vessel network and for cell seeding in the parenchyma, enabling extensive remodelling while maintaining an open-vessel lumen. The incorporation of nanopores and micro-holes in the vessel walls enhances permeability, and permits intercellular crosstalk and extravasation of monocytes and endothelial cells on biomolecular stimulation. We also show that vascularized hepatic tissues and cardiac tissues engineered by using
\end{abstract}

Users may view, print, copy, and download text and data-mine the content in such documents, for the purposes of academic research, subject always to the full Conditions of use:http://www.nature.com/authors/editorial_policies/license.html\#terms

*Correspondence should be addressed to M.R. (; Email: m.radisic@utoronto.ca).

AUTHOR CONTRIBUTION

B.Z. developed AngioChip concept, designed and performed experiments, analyzed data and prepared the manuscript. M.M. contributed to mechanical testing, polymer characterization, sprouting assay, blood perfusion experiment, and vascular anastomosis surgery. M.D.C. performed primary rat hepatocyte isolation and urea assay. S.O. differentiated hESC-derived hepatocytes. A.K. performed polymer mechanical testing. A.P. differentiated hESC-derived cardiomyocytes and contributed to the whole blood perfusion experiment and optical mapping. L.A.W. performed extraction of human whole blood. S.M. and K.N. performed optical mapping measurements and analysis. J.K. performed mass spectrometry analysis. L.R. contributed to the direct vascular anastomosis surgery, A.M. performed the direct vascular anastomosis surgery, S.S.N. contributed to the direct vascular anastomosis surgery and writing of the manuscript. A.W. contributed to the writing of the manuscript. G.K. contributed to the writing of the manuscript. M.V.S. contributed to writing of the manuscript. M.R. envisioned the AngioChip concept, supervised the work and wrote the manuscript.

COMPETING FINANCIAL INTERESTS

Milica Radisic and Boyang Zhang are amongst co-founders of TARA Biosystems and they hold equity in this company. 
AngioChips process clinically relevant drugs delivered through the vasculature, and that millimeter-thick cardiac tissues can be engineered in a scalable manner. Moreover, we demonstrate that AngioChip cardiac tissues implanted via direct surgical anastomosis to the femoral vessels of rat hindlimbs establish immediate blood perfusion.

Recapitulating vascular interfaces of different organs in 3-D is critical in both organ-on-achip $^{1}, 2,3$ and tissue engineering applications ${ }^{4}{ }^{4}$. 3-D micro-tissues composed of parenchymal cells have often been studied in the absence of vasculature ${ }^{9-11}$, whereas vasculature-on-achip has primarily been studied separately from the parenchymal cells ${ }^{12 \_14}$. A similar vascularization challenge has been experienced on the macro-scale. Numerous tissue types have been successfully engineered in vitro, but clinical translation has been achieved only for thin tissues or those with a low metabolic demand (e.g. skin, cartilage and bladder) ${ }^{15}$. Large solid tissues (e.g. myocardium, liver) are highly sensitive to oxygen levels and become vulnerable within hours without oxygen supply ${ }^{15-17}$. These tissues would greatly benefit from rapid vascularization in vitro and direct vascular integration in vivo. Although elegant approaches have been described that enable anastomosis of oriented engineered capillaries to the host vasculature with perfusion several days after implantation ${ }^{18}$, direct surgical anastomosis with immediate perfusion of vascularized tissues has only been demonstrated using vascular explants ${ }^{19}, 20$, requiring multiple surgeries to harvest the vascular bed.

Vascular networks can be engineered with subtractive fabrication by embedding a sacrificial carbohydrate-glass lattice ${ }^{3}, 21$, Pluronic $\mathrm{F} 127^{3}$, dry alginate fibers ${ }^{22}$, or gelatin ${ }^{23}$ in hydrogels. However, the soft hydrogel provides only temporary structural support for the fragile hollow network and does not permit extensive tissue remodeling ${ }^{21}$, which inevitably alters the hydrogel structure and collapses the embedded network. Synthetic biodegradable polymers could provide sufficient structural support to the engineered vessels, but their low permeability prevents biomolecule exchange and cell migration between the vessels and the parenchymal space ${ }^{24 \_26}$.

To accommodate these two opposing material criteria we created AngioChip, a stable biodegradable scaffold with a built-in branching micro-channel network featuring two unique advances realized by our new 3-D stamping technique. First, the synthetic built-in vascular walls were thin and flexible, yet strong enough to mechanically support a perfusable vasculature in a contracting tissue and enable direct surgical anastomosis. Second, to allow efficient molecular exchange and cell migration, nano-pores and microholes were incorporated into the vascular walls. By establishing a stable, permeable, vessel network within AngioChips, we were liberated from material constraints, enabling the use of various extracellular matrices (ECMs) with cells in the parenchymal space and tissue remodelling. The AngioChip parenchymal space structure was also fine-tuned to mimic the anisotropy of native tissues (e.g. myocardium), traditionally difficult to achieve with a homogeneous hydrogel. Based on this methodology, we created functional and vascularized cardiac and hepatic tissues. 


\section{AngioChip scaffold with branching interconnected lumens}

The AngioChip scaffolds were constructed using a biodegradable elastomer, poly(octamethylene maleate (anhydride) citrate) (POMaC) ${ }^{27}, 28$ (Figure 1). POMaC was selected since it is UV-polymerizable, allowing rapid assembly under mild conditions, biodegrades by hydrolysis ${ }^{27}$ (Supplementary Figure 1, 2), and is more elastic than FDA approved polyesters ${ }^{29}$. Citric acid-based elastomers also have low thrombogenicity ${ }^{30}, 31$. Thin POMaC sheets were pre-patterned, in a scalable manner (Figure 1a), under UV illumination and stamped onto each other, layer-by-layer with precise alignment down to several microns, to form complex suspended microstructures and internal cavities. POMaC exhibited temporary and differential adhesion to glass (strong) and polydimethylsiloxane (PDMS) (weak) after photo-crosslinking, due to oxygen-induced inhibition of free radical polymerization on the surface of the $\mathrm{PDMS}^{32}$, which leaves a non-polymerized POMaC layer at the interface. Patterned POMaC sheets were robustly transferred, aligned and released from one substrate (PDMS) then bound to the POMaC structures supported by a glass substrate (Supplementary Figure 3), circumventing the challenge of printing biomaterials in mid-air ${ }^{33}$. 3-D stamping enabled patterning of $\mathrm{POMaC}$ into various intricate structures from a 1-D tube (Figure 1e) to 2-D bifurcating conduits (Figure 1f) or a 3-D branching network (Figure 1g) mimicking a vascular bed within a fully interconnected lattice matrix, tailored to support the parenchymal cells (Figure 1c,d,f,gSupplementary Figure 4).

Internal networks branching in the $x-y$ as well as $y-z$ planes were perfusable through a single inlet and outlet (Figure 1b,f,g, Supplementary Figure 4, Movie 1). The smallest microchannel in the network was $100 \mu \mathrm{m}$ by $50-100 \mu \mathrm{m}$, with a wall thickness of $25-50 \mu \mathrm{m}$. To improve the exchange of biomolecules and cell migration, $10 \mu \mathrm{m}$ micro-holes were patterned in the upper channel walls (Figure 1h-j, Supplementary Figure 5a,b). To increase porosity, $20 \mu \mathrm{m}$ micro-holes were patterned in the top and side channel walls (Figure 1k,l,

Supplementary Figure 5c). To further enhance oxygen and nutrient exchange, nano-pores were incorporated into the bulk polymer by embedding and subsequently leaching out a porogen, confirmed by mass reduction (Figure 1m) and resulting in wrinkled nano-pores, as described $^{34}$ (Figure 1n).

For perfusion culture, the AngioChip scaffolds were installed in the main well between the inlet and outlet well of a customized bioreactor (Figure 1c, Supplementary Figure 6). Culture medium or endothelial cell (EC) suspension was perfused through the internal network driven by the liquid pressure head differences (Figure 1c, Supplementary Figure 7). This design removed the need for pumps, allowing access to both the parenchymal space and the internal vasculature using simple tools (e.g. micropipettes), and enabling facile tissue removal (Figure 1b). ECs were cultured within the internal network while the parenchymal cells were cultured within the lattice with native ECMs, allowing tissue remodelling (Figure 1d). 


\section{Tunable elasticity and permeability of AngioChips}

The hydrolytically degradable scaffold lattice (Supplementary Figure 8a,b) was composed of multiple layers of meshes in the parenchyma connected by vertical posts $(50 \mu \mathrm{m}$ diameter) (Figure 1i). This feature provided 100\% interconnectivity (Figure 1g), facilitating cell seeding and enabling formation of tissues in both the $x-y$ and $y-z$ plane. The Young's modulus of the adult human myocardium was reported to vary from $10-20 \mathrm{kPa}$ (relaxed) to $200-500 \mathrm{kPa}$ (contracted) ${ }^{35} 38$, while for adult liver it varied from $0.6-2.0 \mathrm{kPa}$ for healthy and up to $20 \mathrm{kPa}$ for fibrotic livers ${ }^{39}$. By varying the UV and heat exposure, monomer ratio and porogen concentration we were able to achieve the Young's Modulus of POMaC bulk polymer ranging from $53 \pm 8$ to $1423 \pm 651 \mathrm{kPa}$ (Figure 2d, Supplementary Figure 8c, Supplementary Table 1-4).

The geometry and density of the AngioChip parenchymal lattice were further varied to finetune the scaffold mechanical properties to resemble the anisotropic properties of the adult rat ventricular myocardium as in design B (Figure 2a-c, e, Supplementary Figure 9-10,

Supplementary Table 5). Anisotropy was enabled by the rectangular shape of the mesh, with higher spatial density for struts oriented in the long-edge direction (LD) than in the shortedge direction (SD) (Figure 2e). Both the effective elasticity (E) and the ultimate tensile strength (UTS) increased with lattice density. Further design iterations can yield scaffolds with mechanical properties tailored for specific applications (e.g. human myocardium or human liver) by tuning the lattice structure and the elasticity of the base material (Figure 2d).

The limited permeability of synthetic polymers hinders the success of other biodegradable microfluidic scaffolds ${ }^{24}, 25$. Although some biocompatible polymers are permeable to $\mathrm{O}_{2} / \mathrm{CO}_{2}{ }^{40}$, they have a limited permeability for small molecules and proteins ${ }^{41}$ necessitating introduction of porosity to enhance permeability (e.g. as in transwell membranes, $9.3 \times 10^{-5} \mathrm{~cm} / \mathrm{s}$ for $4 \mathrm{kDa}$ molecules ${ }^{42}$ ). We found the cell-free internal AngioChip network with $10 \mu \mathrm{m}$ micro-holes was permeable to both small and large molecules (Figure 2f,g). It was $>4$ times more permeable for large molecules (70kDa TRITC-dextran) than the one without the $10 \mu \mathrm{m}$ micro-holes, $>2$ times more permeable than EC-covered network and more permeable than mammalian venules and capillaries in vivo (Figure 2f). The permeability of the EC-covered network was higher than the permeability of mammalian venules $\left((0.15 \pm 0.05) \times 10^{-6} \mathrm{~cm} / \mathrm{s}\right)$ for $70 \mathrm{kDa}$ FITC-Dextran ${ }^{43}$ and comparable to that of capillaries ${ }^{44}$ to proteins $\left(4.3 \times 10^{-6} \mathrm{~cm} / \mathrm{s}\right)$. High permeability of the cell-free network allowed the EC coating to be the dominating transport resistance (Figure 2f), similar to how the ECs govern the permeability of blood vessels in vivo. The live cell tracker dye, carboxyfluorescein diacetate (CFDA, 557Da), was perfused through the network surrounded by cardiac cells, staining the live cells in the parenchyma (Figure $\mathbf{2 h}$ ), consistent with convection-diffusion transport and metabolic conversion within the tissue. There was no significant leakage of the culture media during perfusion into the parenchymal space even in the absence of the endothelial cell coating (Supplementary Figure 8d). The AngioChip burst pressure was comparable to that of the rat femoral vein (Figure 2i, Supplementary Movie 2) and $\sim 7$ fold higher than the normal systolic blood pressure in a rat $(130 \mathrm{mmHg}$ ) or 
a human $(120 \mathrm{mmHg})$, indicating the network will be sufficient to withstand blood perfusion in the peripheral circulation.

\section{Lumen endothelialisation with on-demand sprouting and cell trans- migration}

Upon endothelialization with human umbilical vein ECs (HUVECs), CD31 immunostaining revealed a confluent endothelium on the luminal network surface (day 2, Figure 3ad; Supplementary Figure 11a-c, day 7 Supplementary Figure 11e-h) with VE-cadherin expressed at the cell-cell junctions (day 2, Supplementary Figure 11d). The ECs physically covered the micro-holes on the vessel wall (Figure 3b,c, Supplementary Figure 11a-c), conformally and confluently coating the lumen even at the branch points (Supplementary Movie 3). In response to an angiogenic stimulus, thymosin $\beta 4$, ECs migrated through the $20 \mu \mathrm{m}$ micro-holes into the parenchymal space, a first step of angiogenesis (Figure 3e-g). Endothelial network permeability dynamically increased in response to this biological stimulus (Figure 3h), a feature unique to living cells that cannot be reproduced using the polymer material alone. Human whole blood was perfused through the AngioChip network with or without EC coating at $15 \mathrm{dynes} / \mathrm{cm}^{2}(\sim 5 \mu \mathrm{L} / \mathrm{min}$; Re, 0.023$)$ (Figure 3i). The AngioChip network was designed so that the ECs in the first and second order branches experienced the same shear stress. Without an EC coating, more platelets bound to the network surface (Figure 3i-ISupplementary Figure 12) and became activated, as indicated by their extended pseudopodal morphology (Figure 3j). Attached platelets exhibited a trend to spread according to the blood flow pattern and accumulated more at the stagnation regions of branches and turns (Figure 3j, Supplementary Figure 12). Perfused human monocytes, THP-1, exhibited accumulation and adhesion in the network in response to an inflammatory stimulus, TNF-a, (Figure 3m-p), subsequent migration along the endothelialized surface (Figure 3q) and trans-migration through the $10 \mu \mathrm{m}$ micro-holes on the vessel walls, into the parenchymal space (Figure 3r). The AngioChip was versatile enough to also enable migration of Raw264.7 macrophages (Supplementary Figure 13).

\section{Urea secretion and drug metabolism in vascularized liver}

Primary rat hepatocytes mixed with $10 \%$ primary rat fibroblasts (to facilitate ECM remodelling and gel compaction ${ }^{9}$ ) were seeded into the parenchymal space of an endothelialized AngioChip scaffold, resulting in the aggregation of viable cells (Figure 4ae, Supplementary Figure 14a). Hepatocytes (albumin stained) distributed throughout the lattice and around the vessel network, while ECs (CD31 stained) coated the inner lumen of the network (Figure 4a-c). Hepatic tissues were challenged with terfenadine, an antihistamine withdrawn from the market due to cardio-toxicity ${ }^{45}$ (Figure 4f-g). Terfenadine is generally metabolized in the liver, to non-cardio-toxic fexofenadine, by the enzyme cytochrome P450 CYP3A4 isoform ${ }^{45}$. Liquid chromatography-mass spectrometry (LC-MS) revealed the presence of fexofenadine in the outlet well (Figure $\mathbf{4 g}$ ).

Entirely human liver-AngioChips were engineered using human embryonic stem cell (hESC) derived hepatocytes ${ }^{46}$, human mesenchymal stem cells (hMSCs) as a supporting 
population and HUVECs for inner lumen coating. High-density culture resulted in the formation of junctions between hepatocytes (Figure 4j), positive staining for albumin (Figure 4k) and bile canaliculi (Supplemental Figure 15), that were similar in appearance to those obtained from a collagen sandwich (Figure $4 \mathbf{h}, \mathbf{i}$ ), a commonly used control. Cell density was $0.6 \pm 0.2 \times 10^{8} \mathrm{cells} / \mathrm{cm}^{3}$ at day 7 with cells present throughout the AngioChip volume and $\mathrm{CD} 31^{+}$ECs coating the inner lumen (Figure 4l,m). Secretion of urea per cell from endothelialized AngioChip tissues was quantified and shown to be higher than that of collagen sandwich control (Figure 4n-o).

\section{Scalable assembly of contractile vascularized cardiac tissue}

Cardiac tissues were created from either hESC-derived (Figure 5a-w, Supplementary Figure 14b, 18) or neonatal rat cardiomyocytes (Figure 5x-z). To provide evidence of tissue-level organization, entire AngioChips based on entirely human cells (hESC-derived cardiomyocytes, $10 \%$ hMSCs and HUVECs) were imaged using confocal microscopy. Elongated cell bundles were present throughout the entire volume (Figure 5a-f, Supplementary Figure 14b) including the scaffold interior (Figure 51-m, Supplementary Figure 16). Although gel compaction was possible without the addition of supporting cells, tissues were more compacted and aligned when 10\% MSCs were used (Figure 5c,e). Cardiac cell density, estimated from the histology sections, was $2.3 \pm 0.8 \times 10^{8} \mathrm{cells} / \mathrm{cm}^{3}$. A condensed tissue formed within 5 days (Figure 5i, Supplementary Figure 14b, 16); a time frame consistent with previously published studies of non-vascularized cardiac tissues that relied on gel compaction ( 5 days for human ${ }^{5}$ and 7 days for rat ${ }^{47}$ ). Synchronous macroscopic contractions were observed as early as day 4 and the electrical excitability parameters of both rat and human tissues fell within the standard range for non-vascularized rat constructs ${ }^{48}$ and both rat ${ }^{9}, 47$ and human micro-tissues ${ }^{5}$ (Figure 5j, k). AngioChip cardiac tissues contracted macroscopically and compressed the scaffold at each beat

(Supplementary Figure 17b) without collapsing the internal vessel network while being perfused (Supplementary Movie 4,5). The contractile protein sarcomeric a-actinin and the structural protein F-actin were visible in the elongated cells (Figure 5d,f; Supplementary

Figure 16). Striated cardiac tissue bundles of the AngioChip were similar to those present in the 3D Biowire construct, a control that previously improved cardiomyocyte structural maturation ${ }^{5}$ (Figure 5g). Cardiomyocytes cultivated in monolayers, a standard control, exhibited cross-striations, but a lack of overall orientation and a less anisotropic overall structure (Figure 5h) compared to those cultured in AngioChips (Figure 5f). At day 7, ECs coated the vessel lumen, while cardiomyocytes distributed throughout the lattice and packed around the vessels (Figure 5l-m). Human cardiac tissue exhibited impulse propagation across the entire tissue $(4.8 \pm 1.3 \mathrm{~cm} / \mathrm{s}, \mathrm{n}=7)$, without conduction block (Figure $5 \mathrm{n}$,

Supplementary Movie 6). These values are lower than conduction velocities (voltage) we reported for Biowires previously ${ }^{5}$, as AngioChips were cultivated for a shorter period of time and without electrical stimulation. Conduction velocity can be further improved by electromechanical stimulation ${ }^{5}, 49$. Within 30-40min of application, the tissues showed the expected positive chronotropic response to epinephrine $(10 \mu \mathrm{M}$, Figure 5o,p,

Supplementary Figure 17A). 
Engineering millimetre-scale thick tissues was possible using two scalable approaches: 1) by fabricating multilayer scaffolds (1.58mm thick, Figure 5q, Supplementary Figure 20a) via the 3D stamping technique with one inlet and one outlet (Figure 5q-w, Supplementary Figure 20) or 2) by stacking individual single-layer AngioChip tissues followed by the cultivation under perfusion to create a single multi-layer thick tissue with multiple inlets and outlets (Supplementary Figure 19). Fibrin gel or Matrigel hydrogel were independently used demonstrating versatility of hydrogel choices for parenchymal cell seeding. The resulting cardiac tissue was $1.75-2 \mathrm{~mm}$ thick with a high density of elongated cells throughout the cross-section (Figure 5s-u, Supplementary Figure 20g,h) and visible crossstriations in the cells from the scaffold interior even after only 3 days in culture (Supplementary Figure 20i). Although the tissue was based on human cardiomyocytes, it was comparable to the thickness of a physiological structure, the adult rat heart left ventricle (Figure 5r).

The inner lumen of the AngioChip scaffold in the thick tissues were fully endothelialized, with organization of endothelial tubule-like structures in the parenchymal space to provide additional level of endothelialization (Figure 5v-w, Supplementary Figure 20f,j-l). In some instances these tubular structures clearly connected with the endothelial cells sprouting, through the $20 \mu \mathrm{m}$ micro-holes, from the inner luminal structures of the AngioChip scaffolds (Supplementary Figure 20f,j-l), demonstrating the direct interaction of the cells in the two compartments.

Rat cardiac tissue (Figure 5x) exhibited higher viability under perfusion compared to the non-perfused controls, which developed a necrotic core at day 7 (Figure 5y). The most cell death (i.e. lactate dehydrogenase release) occurred within the first 3 days and medium perfusion helped mitigate cell death (Figure 5z) on day 3, clearly demonstrating the benefit of perfusion even for the single-layer AngioChip tissues.

\section{Direct surgical anastomosis of AngioChips to host vasculature}

AngioChip scaffolds were connected to the femoral vessels on the hindlimbs of adult Lewis rats, in artery-to-artery (Figure 6a) and artery-to-vein (Figure 6b) mode, to demonstrate two different configurations of direct surgical anastomosis. The inlet and outlet (inner dimensions of $100 \mu \mathrm{m} \times 200 \mu \mathrm{m}$ and outer dimensions of $300 \mu \mathrm{m} \times 400 \mu \mathrm{m})$ were connected to femoral vessels (Figure 6) with surgical cuffs. Similar citric acid-based polymers ${ }^{28}$ have been shown to be antithrombotic in vascular grafts and to support EC growth in vivo ${ }^{30}, 31$. The animals were only heparinized during surgery. In both configurations, blood perfusion was established immediately, even in the absence of ECs (Figure 6a-b), although artery-toartery mode was more technically challenging due to the higher pressure (Supplementary Movie 7). Blood pulsation was also observed (Supplementary Movie 7), more noticeably in the artery-to-artery configuration. Erythrocytes were only observed in the networks of tissues implanted with direct anastomosis (Figure 6c,d,g,h,k, Supplementary Figure 21,22). One week after the implantation of the AngioChip cardiac tissues, native angiogenesis also took place around the implants (Supplementary Figure 23). The presence of smooth muscle actin (SMA) positive cells was merely $2 \%$ in the isolated neonatal rat heart cells ${ }^{4}$; the significant SMA staining (Figure 6e,i, Supplementary Figure 24) 
suggested the penetration of mural cells or myofibroblasts into the implanted tissues consistent with the healing response ${ }^{50}$ (Figure 6l). Troponin $\mathrm{T}$ immuno-staining demonstrated some elongated cardiomyocytes intertwining within the lattice of the AngioChips (Figure 6f, j, Supplementary Figure 25). AngioChip cardiac tissues endothelialized with Lewis rat primary vein ECs were also implanted via direct anastomosis in the artery-to-vein configuration. One week later, ECs coating the lumen were observed in $50 \%$ of the micro-channels from three different implants $(2 / 5,4 / 5,1 / 5$ of visible lumen for implant 1,2,3, respectively) (Figure 6m-p). Histologically, 85\% of AngioChip lumen were blood clot-free after 1 week in vivo (Supplementary Figure 21, 22). Specifically, in nonEC coated AngioChips 3/3, 3/3, 4/5 and 3/5 of visible lumen were blood clot-free in the four implants and in the EC coated groups $3 / 5,5 / 5,5 / 5$ were blood-clot free in the three implants. The channel walls did not degrade appreciably in one week, indicating that longer time is required, as biodegradation and biocompatibility studies showed POMaC polymer discs persisted for at least 5 weeks in vivo (Supplementary Figure 26).

\section{Outlook}

AngioChip provides a powerful platform technology for cultivation of vascularized tissues that overcomes key limitations in the fields of tissue engineering (scalable production of mm-sized tissues), organ-on-a-chip engineering (precise placement of endothelial and parenchymal cells, in a simple to operate format) and in vivo tissue implantation (direct anastomosis). This technology liberates the cells from the requirement to be in direct contact with drug-absorbent PDMS in a closed channel system for organ-on-a-chip application or to rely on hydrogels as the sole carrier that is too fragile to surgically connect into the hosts' circulation for in vivo implantation. Here, we effectively decoupled the material choice for the engineered vessel network from the material choice for the parenchymal-space, allowing us to control the initial architecture of the vasculature and establish immediate perfusion in vitro and in vivo while sustaining the extensive remodelling of parenchyma. This microengineering approach provided no delay for tissue endothelialization, as perfusable endothelial network was achieved within one day, prior to parenchymal cell seeding. The new 3-D stamping technique allowed us to handle polymer sheets as thin as $25 \mu \mathrm{m}$ with $10-20 \mu \mathrm{m}$ holes to create a vessel wall that is merely 2-3 cells thick. Thus paracrine signalling between the ECs and the parenchyma, that usually decays significantly within a very short distance $(\sim 10 \text { cells })^{51}$, can be sustained.

The thin channel walls in combination with the nano-pores and micro-holes were the key features that allowed effective molecular exchange, cell extravasation in a vascularized 3-D tissue model, and physiologically relevant modes for delivery of test drugs by convectiondiffusion. The addition of $10 \mu \mathrm{m}$ micro-holes covering only $0.5 \%$ of the total network surface area increased the permeability of the network by more than 4 times compared to the microhole free scaffolds. The resulting permeability was higher than that of the native vasculature for EC-free AngioChips, ensuring that the polymer wall did not inhibit transport and enabling subsequent EC-coating to act as a governing resistance. AngioChip networks with $20 \mu \mathrm{m}$ micro-holes in the top and sidewalls increased the coverage of micro-holes to $3.2 \%$ of the surface area and guided the endothelial sprouts into the parenchyma. To further fine-tune the vessel permeability to match the unique environment in different organs, organ specific 
ECs should be used. AngioChip also enables fine-tuning of the elasticity for specific organs, a factor important for preventing long term inflammation and fibrosis ${ }^{52}$, using a rectangular (for anisotropic ${ }^{53}$ ) or square (for isotropic ${ }^{54}$ ) lattice in the parenchymal-space, difficult to achieve with hydrogels ${ }^{21}$.

The AngioChip platform enables facile integration of different tissues on a single device by linking multiple AngioChips in series (Supplementary Figure 27). Conventional microfluidic systems require bulky external setups that make integration difficult. Closed chip configuration is incompatible with the current practices in biological laboratories and pharmaceutical industry, which rely heavily on open access for liquid dispensing with micro-pipetting. Our platform, resembling a standard multi-well plate, maintains an open configuration so that both the parenchymal space and the internal vasculature can be accessed with pipetting and allows different media to be used in each compartment, thus facilitating co-culture.

Long-term patency of the AngioChip networks should be determined in future in vivo studies. Immobilization of heparin onto the inner luminal surface with existing methods $50,55,56$, could also enhance long-term blood vessel patency. Appropriate scaffold degradation rate is critical $^{50}$; therefore, long-term degradation of the AngioChip in vivo should be examined in the future and fine-tuned for a specific application by adjusting the citric acid content on the polymer-chain ${ }^{27}$ to enable native mural cells and ECM to gradually take over the role of the synthetic polymer vessel wall. Future studies should determine if the original blood vessels will remain, upon complete AngioChip biodegradation, and if the endothelialized vasculature will exhibit appropriate vasodilation and vasoconstriction properties in vivo. Other non-thrombogenic, photo-crosslinkable scaffold materials, with tissue-specific elasticity, could be explored. Electrical stimulation during cardiac culture on AngioChips should be used to further synchronize tissue contractions and mature cells ${ }^{5}$. The proof-of-concept for the use AngioChip in organ-on-a-chip engineering provided here opens the door for future studies aimed at answering complex biological questions in vitro and in vivo.

In summary, the AngioChip was used to generate both in vitro cardiac and hepatic tissue models with defined vasculature and in vivo implants with direct surgical anastomosis. Uniquely, this platform could enable direct and rapid translation of in vitro testing results to in vivo validation and the development of effective regenerative strategies.

\section{METHODS}

\section{POMaC synthesis}

To prepare poly(octamethylene maleate (anhydride) citrate) (POMaC) prepolymer, 1,8octandiol, citric acid, and maleic anhydride were mixed at 5:1:4 molar ratio and melted at $160^{\circ} \mathrm{C}$ under nitrogen purge. The temperature was dropped to $140^{\circ} \mathrm{C}$ and the mixture was stirred for 2-3hr. The resultant pre-polymer solution was then dissolved in 1,6 dioxane and purified via drop-wise precipitation in deionized distilled water produced from a Direct-Q 5 Water Purification System (Millipore, Billerica, MA). Precipitated polymer was collected and lyophilized for 2 days. Prior to photo-crosslinking, POMaC prepolymer was mixed with 
$5 \%(w / w)$ UV initiator (Irgacure 2959 , Sigma) by melting briefly at around $90^{\circ} \mathrm{C}$. To make nano-porous scaffolds, POMaC polymer was also mixed with a porogen, poly(ethylene glycol) dimethyl ether (PEGDM, Mw 500, Sigma) at 60\% (w/w) (Supplementary Figure 1). Pore-free scaffolds were made without adding PEGDM.

\section{AngioChip Fabrication}

Each layer of the AngioChip scaffold was first generated in AutoCAD and translated to individual SU-8 masters via standard soft lithography techniques as described previously ${ }^{57}$

(Supplementary Figure 3 (step 1)). Micro-hole design was directly incorporated in the AutoCAD drawing for AngioChip scaffolds with micro-holes. Experiments performed using AngioChips with micro-holes were explicitly specified. In AutoCAD, the outer dimensions of the AngioChip were set to $5 \mathrm{~mm}$ length, $3.1 \mathrm{~mm}$ width and one layer thickness of 150-300 $\mu \mathrm{m}$. Silicone elastomer (poly(dimethylsiloxane), PDMS, 1:15 cross-linker ratio) was moulded against the SU-8 masters and cured at room temperature for 2-3 days

(Supplementary Figure 3 (step 2)). Patterned PDMS moulds for the base layer and upper layers of the 3-D scaffold were capped to glass slides and flat PDMS sheets, respectively (Supplementary Figure 3 (step 3)). The POMaC solution was then injected into the patterned network through an inlet and outlet and left overnight at room temperature. Injection was achieved by either a syringe pump applying a gentle pressure to push the POMaC solution through the mould without delaminating the mould or by a drop of the polymer solution applied on top of the inlet holes to apply a gentle positive pressure. Overnight, the POMaC solution filled the entire PDMS moulding including the vertical column extending out from the main mesh network. The gentle positive pressure at the inlet pushed out any trapped air inside the mould since the PDMS was porous and allowed air to escape (Supplementary Figure 3 (step 4)). Next, injected POMaC solution was crosslinked under UV light at an intensity of $10 \mathrm{~mJ} / \mathrm{cm}^{2}$ s for $4 \mathrm{~min}$, for the polymer mixed with the porogen, 60\%(w/w) PEGDM/ POMaC solution, or 10min if no PEGDM was added. Afterwards, the PDMS moulds were uncapped and the patterned polymer structures were exposed (Supplementary Figure 3 (step 5)). The patterned POMaC sheets for the first layer were attached onto the glass slides while the patterned POMaC sheets for the following layers were attached onto the PDMS moulds. The exposed POMaC sheets on the PDMS moulds were then aligned to and pressed against the patterned POMaC sheets on the glass slides with a customized UV mask aligner (Q2001, Quintel Co., CA) (Supplementary Figure 3 (step 5)). To bond the layers together, the samples were then exposed to UV at an intensity of $10 \mathrm{~mJ} / \mathrm{cm}^{2} \mathrm{~s}$ for $4 \mathrm{~min}$ or $10 \mathrm{~min}$ if no PEGDM was added. After the UV exposure, the PDMS moulds were released, leaving the two patterned POMaC sheets bonded together and attached to the glass slides (Supplementary Figure 3 (step 5)). This process was repeated to bond additional patterned POMaC sheets to the established base structure (Supplementary Figure 3 (step 6)). Lastly, fabricated scaffolds were immersed in phosphate buffered saline (PBS) to release them from the glass slides and incubated overnight at room temperature to leach out the PEGDM porogen. Multiple scaffolds were patterned in parallel on a single glass slide in a single process (Figure 1 a). Additional tips for AngioChip scaffold fabrication are described in Supplementary Methods. AngioChip scaffolds structure, degradation properties, burst pressure, mechanical properties and 
permeability were characterized as described in the Supplementary Methods. Material biocompatibility in vivo was assessed as described in Supplementary Methods.

\section{Bioreactor design}

The bioreactor was composed of four components: a cap, a polycarbonate body, a PDMS base, and a polycarbonate base (Figure 1 c, Supplementary Figure 6). The bioreactor was designed to accommodate three scaffolds in separate chambers at a time. The polycarbonate body ( $2.5 \mathrm{~cm}$ thick) included 9 wells positioned in three rows: the top row encompassed the inlet wells, the middle row encompassed the main wells, where the AngioChip scaffolds were positioned, and the bottom row encompassed the outlet wells. The PDMS slab (1 mm

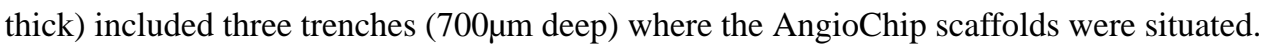

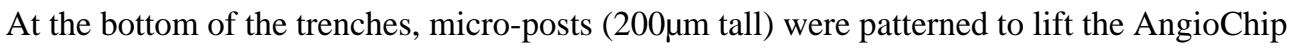
scaffolds up from the base so that cells/gel can penetrate underneath the scaffolds and encapsulate the entire scaffolds. The trench also included an open inlet and outlet channel where the inlet and outlet of the AngioChip scaffolds could precisely fit. After the AngioChip scaffolds were positioned, the PDMS base was then sandwiched between the polycarbonate base and the polycarbonate body so that the open inlet and outlet channels on the PDMS base were capped with the inlet and outlet of the AngioChip fitted within. The three components were secured with stainless steel screws.

When assembling the AngioChip scaffold onto the bioreactor, it is crucial to not apply excessive pressure onto the scaffold inlet and outlet by screwing the bioreactor too tight. Excessive pressure applied could constrict the inlet and outlet channel and reduce the flow rate. To prevent leakage of fluid around the inlet and outlet of the scaffold, a drop (around $10 \mu \mathrm{L})$ of $1 \%(\mathrm{w} / \mathrm{v})$ agarose solution sterilized and heated to $80^{\circ} \mathrm{C}$ can be applied around the connection of the inlet and outlet to seal any gaps (Figure $1 \mathbf{c}$ (step 1)).

After assembling the scaffold onto the bioreactor, the bioreactor was filled with culture media and incubated at $37^{\circ} \mathrm{C}$ to prime the scaffold overnight, prior to cell seeding. Since the assembly was done at room temperature, when the bioreactor was placed in the incubator at $37^{\circ} \mathrm{C}$; the increase in temperature could lead to the expansion and elimination of any bubbles trapped within the scaffold network. Ethanol should not be used to prime the scaffold at this stage since ethanol significantly swells the scaffold and results in failure in the inlet and outlet connection (Figure $1 \mathrm{c}$ (step 1)).

Solution and/or cell suspensions were perfused from the inlet wells through the built-in networks of the AngioChip scaffolds to the outlet wells driven by a pressure-head difference between the inlet and outlet wells (Supplementary Figure 7). The bioreactor was disassembled in sterile conditions to remove the AngioChip tissues for implantation or analysis. When applying parenchymal cells in hydrogel around the scaffold, $10 \mu \mathrm{L}$ of the gel/ cell suspension was first applied to the scaffold, allowing the cells to fall through the lattice matrix of the scaffold to fill the space under the scaffold as well as the lattice matrix. Then after $10 \mathrm{~min}$ of incubation at $37^{\circ} \mathrm{C}$, an additional $5 \mu \mathrm{L}$ of the gel/cell suspension was applied on top of the scaffold to fully encase the scaffold in gel/cell suspension. This sequential seeding method helped ensure more even seeding. If all the gel/cell suspension was applied at once, the scaffold would tend to float to the surface of the suspension and result in less 
cell/gel on the upper surface of the scaffold (Figure 1 c (step 3)). To examine the fluid flow through the AngioChip scaffold in the bioreactor, AngioChip scaffolds with $10 \mu \mathrm{m}$ microholes and without endothelial cell coating were perfused by adding $4 \mathrm{~mL}$ of PBS in the inlet wells and $1 \mathrm{~mL}$ of PBS in the main wells. After $24 \mathrm{hr}$ incubation at $37^{\circ} \mathrm{C}$, the PBS was collected from the inlet, main, and outlet wells and weighted to determine fluid distribution in different compartments.

\section{Cell maintenance and differentiation}

Human umbilical vein endothelial cells (HUVECs) were purchased from Lonza and cultured with endothelial growth medium (EGM2, Lonza). Lewis rat vein endothelial cells were purchased from CellBiologics and cultured with Complete Rat Endothelial Cell Medium (CellBiologics). Human mesenchymal stem cells (hMSCs) were gifts from Dr. Armand Keating's lab at University Health Network, Toronto, Canada. hMSCs were isolated from a healthy person under 40 years of age. hMSCs were expanded and cultured in Dulbecco's Modified Eagle Medium (Gibco) with 10\%(v/v) fetal bovine serum (Gibco), $1 \%$ (v/v) HEPES (100units/mL, Gibco) and 1\%(v/v) penicillin-streptomycin $(100 \mathrm{mg} / \mathrm{mL}$, Gibco). Undifferentiated H9 (WA09) human embryonic stem cells (hESCs) were maintained, differentiated into hepatocytes and cultured as previously described ${ }^{46}$. To inhibit notch signaling, gamma-secretase inhibitor (GSI) L-685,485 (10uM:Tocris) was included in the medium throughout the culture period on AngioChip. Primary rat hepatocytes were isolated using a modified two step isolation procedure from 8 week old male Sprague Dawley rats ${ }^{58}$ according to a protocol approved by the University Toronto Animal Care Committee. Neonatal rat cardiomyocytes and fibroblasts were isolated by digesting neonatal rat hearts as described previously according to a protocol approved by the University of Toronto Animal Care Committee ${ }^{57}$. HES-3 NKX2-5 GFP positive cells were maintained, differentiated to human cardiomyocytes, and cultured using previously described techniques 5960 .

\section{Endothelialization and tissue assembly}

To enhance cell attachment onto the AngioChip scaffolds as well as within the internal network, the scaffolds were coated with $0.2 \%$ (w/v) gelatin (from porcine skin, Type A, Sigma) in phosphate buffered saline (PBS) for $2 \mathrm{hr}$ prior to assembly. To prevent cell attachment onto the PDMS base, it was coated with 5\% (w/v) Pluronic F-127 (Sigma) in PBS for $2 \mathrm{hr}$ prior to assembly. After the AngioChip scaffolds were placed in the bioreactor, endothelial cells were first seeded into the built-in network of scaffolds by perfusing $10-20 \mu \mathrm{L}$ of concentrated endothelial cell suspension $(25 \mathrm{million}$ cells $/ \mathrm{mL}$ ) in endothelial cell media into the network for $1 \mathrm{~min}$. The flow was then stopped to allow the cells to attach under static conditions for $2 \mathrm{hr}$. Unattached cells were then flushed by adding $1 \mathrm{~mL}$ of endothelial cell media to the inlet wells thus initiating perfusion through AngioChip scaffolds under a flow rate less than $0.7 \mu \mathrm{L} / \mathrm{min}\left(0.62\right.$ dynes $\left./ \mathrm{cm}^{2}, \mathrm{Re}, 0.01\right)$ to apply minimal stress to the cells while feeding the cells with sufficient media. After $2 \mathrm{hr}$ incubation, $3 \mathrm{~mL}$ of EC media was then added to increasing the flow rate to near a one-day average perfusion rat of $0.7 \mu \mathrm{L} / \mathrm{min}$. Within the network, the endothelial cells were allowed to proliferate and form a confluent network overnight (the bioreactor can be temporarily tilted at $45^{\circ}$ angle to increase perfusion rate and accelerate EC proliferation overnight). Prior to the seeding of 
parenchymal cells, all EC media were removed from the bioreactor. On day 1, to create an AngioChip hepatic tissue, primary adult rat hepatocytes or hESCs derived hepatocytes mixed with $20 \%$ hMSCs were seeded at 100-200million cells $/ \mathrm{mL}$ with $15 \mu \mathrm{L}$ Matrigel (BD Biosciences) onto the AngioChip scaffolds. To create a rat AngioChip cardiac tissue, cardiomyocytes isolated from neonatal rats were seeded with $15 \mu \mathrm{L}$ (single layer network) collagen/Matrigel mixture at 100-200 million cells/mL onto each AngioChip scaffold. The composition of the collagen/Matrigel mixture was as follows: $2.5 \mathrm{mg} / \mathrm{mL}$ of rat tail collagen type I (BD Biosciences) neutralized by $1 \mathrm{~N} \mathrm{NaOH}$ and $10 \times \mathrm{M} 199$ media as described by the manufacturer, supplemented with $4.5 \mu \mathrm{g} / \mathrm{ml}$ glucose, $1 \%$ HEPES, $10 \%$ (v/v) Matrigel (BD Biosciences), and $2 \mu \mathrm{g} / \mathrm{ml} \mathrm{NaHCO}_{3}$. To create a human AngioChip cardiac tissue, hESCs derived cardiomyocytes mixed with or without $10 \%$ hMSCs were seeded with $15 \mu \mathrm{L}$ (single layer network) Matrigel (BD Biosciences) at 100-200million cells/mL onto each AngioChip scaffold. After $30 \mathrm{~min}$ gelation at $37^{\circ} \mathrm{C}, 1 \mathrm{~mL}$ of hepatocyte media or cardiomyocyte media was added to the middle well. After the seeding of parenchymal cells, an additional $4 \mathrm{~mL}$ of endothelial cell media was also added to the inlet wells, increasing media perfusion rate back to a one-day average perfusion rate of $0.7 \mu \mathrm{L} / \mathrm{min}\left(0.62\right.$ dynes $\left./ \mathrm{cm}^{2}, \mathrm{Re}, 0.01\right)$. As a control, hepatocyte collagen sandwich culture was used by first plating hESCs derived hepatocytes with $20 \%$ hMSCs on 48 well plates ( 0.14 million cells per well). Attached cells were then encapsulated with collagen $(500 \mu \mathrm{L}$ per well). As a control for cardiac cell culture, cardiac Biowires were formed by seeding hESCs derived cardiomyocytes with $10 \%$ hMSCs around a surgical suture according to a previously published protocol ${ }^{5}$. Cardiac monolayer culture was formed by seeding hESCs derived cardiomyocytes with $10 \%$ hMSCs on 96 well plates $(0.02$ million cells per well).

Thick cardiac tissues were assembled by centrifugation-facilitated cell seeding of the thick AngioChip scaffolds with $20 \mu \mathrm{m}$ micro-holes. The built-in network of the AngioChip scaffold was first endothelialized and cultured for one day. Around 30-40million cells made up of $20 \%$ endothelial cells (HUVECs), $20 \% \mathrm{hMSCs}$, and $80 \% \mathrm{hESC}$ derived cardiomyocytes were mixed with $40 \mu \mathrm{L}$ of fibrinogen $(33 \mathrm{mg} / \mathrm{mL})$. Total of $40 \mu \mathrm{L}$ parenchymal cell solution was pipetted onto each thick scaffold at once followed by centrifugation at $87 \mathrm{~g}$ for $3 \mathrm{~min}$. Alternatively, 3 batches of $14 \mu \mathrm{L}$ cell solution were sequentially pipetted followed by centrifugation after each batch at $28-87 \mathrm{~g}$ for $1 \mathrm{~min}$ (the centrifuge should be well balanced to ensure a smooth spinning-speed acceleration). Finally, $5 \mu \mathrm{L}$ of thrombin $(25 \mathrm{U} / \mathrm{mL})$ was added to the top of the tissue to induce gelation. Seeding with Matrigel was performed in a similar fashion only with temperature control set at $4^{\circ} \mathrm{C}$. An extended bioreactor column was added to the bioreactor to increase the height of the bioreactor chambers to generate a higher-pressure head to increase perfusion for the thick tissue. Fifty $\mathrm{mL}$ of endothelial cell media was added to the inlet chamber and $15 \mathrm{~mL}$ of cardiomyocyte media were added to the main chamber of the AngioChip bioreactor. Both media were supplemented with $10 \mu \mathrm{g} / \mathrm{mL}$ Aprotinin.

For the tissue stacking approach, 3 endothelialized single-layer AngioChip cardiac tissues were seeded with human cells and cultured as described above for 3 days. They were then removed from their individual bioreactor wells and then stacked onto each other in a new bioreactor with $1.5 \mathrm{~mm}$ deep main tissue well. The three tissues were held in place during cultivation with U-shaped stainless steel micro-pins. 


\section{Tissue characterization}

Endothelial sprouting from AngioChip, whole blood perfusion, monocyte and macrophage adhesion and migration on the AngioChip vasculature were performed as described in detail in the Supplementary Methods. Histology, immunostaining and quantification of cell density in AngioChip hepatic and cardiac tissues was assessed as described in Supplementary Methods. Urea assay on hepatic tissue and liver drug testing were performed as described in Supplementary Methods. Functional characterization of engineered cardiac tissue, lactate dehydrogenase (LDH) assay on cardiac tissue and cardiac drug testing were performed as described in Supplementary Methods.

\section{Rat femoral vessel surgery}

All procedures below were performed at the Department of Comparative Medicine Animal Facility, University of Toronto, under a protocol approved by the Committee on Animal Care. AngioChip scaffolds alone, those cultured with Lewis neonatal rat cardiomyocytes, or endothelialized AngioChip scaffold cultured with Lewis neonatal rat cardiomyocytes on day 7 were used for the implantation experiments. Lewis rat vein endothelial cells (CellBiologics Inc.) isolated from inferior vena cava tissue of 6-8 week old Lewis rats were used to endothelialize the AngioChip scaffolds for implantation. To demonstrate the ability of AngioChip to be implanted in two different ways via a direct anastomosis in vivo, we used two different configurations: artery bypass configuration and artery-to-vein configuration. To improve the mechanical stability of the anastomosis site, the inlet and outlet segment of the AngioChip scaffold were made without the use of porogen. During the surgery, adult male Lewis rats $(150-250 \mathrm{~g})$ from Charles River were first anesthetized with 1-3\% isoflurane at flow rate of $1 \mathrm{~L} / \mathrm{min}$. Analgesic was administered $(5 \mathrm{mg} / \mathrm{kg}$ ketoprofen, SQ) and both hindlimbs were prepared for surgery. For the surgical procedure, a dissection microscope was used to obtain an enlarged view of the hindlimb region. Skin was shaved and incisions were made on the left leg, approximately $2 \mathrm{~cm}$ long starting from the knee to the medial thigh. Then, subcutaneous fat tissue and the underlying neurovascular bundle were revealed. The femoral artery and vein were dissected and separated from the nerve. For artery bypass configuration, a segment of the femoral artery (approximately $1.5 \mathrm{~cm}$ in length) was fully exposed and ligated for the insertion of the AngioChip cardiac tissue. The two ends of the artery were clamped with a microsurgical approximating clamp to temporarily stop blood flow during the surgery. One 25 gauge cuff (polyimide tube) was inserted into each end of the artery and secured with 7-0 sutures. Biodegradable surgical cuffs can also be used in future applications ${ }^{61}$. The inlet and outlet of the AngioChip cardiac tissue were then inserted into the cuffs and sealed with tissue glue (Cyanoacrylate). Clamps were then removed and blood perfusion was established. For artery-to-vein configuration, a segment (approximately $5 \mathrm{~mm}$ in length) of the femoral artery and femoral vein was fully exposed and ligated for the insertion of the AngioChip cardiac tissue. The ends of the artery and vein were clamped with a microsurgical approximating clamp to temporarily stop blood flow during the surgery. One 25 gauge cuff (polyimide tube) was inserted into each top end of the artery and vein and secured with 7-0 sutures. The bottom ends of the artery and vein were sealed with 7-0 sutures. The inlet and outlet of the AngioChip cardiac tissue were then inserted into the cuffs and sealed with tissue glue (Cyanoacrylate). Clamps were then removed and blood perfusion was re-established. Lastly, another cardiac tissue patch was implanted to the right leg 
subcutaneously in a similar manner but without anastomosis to serve as a control. For postoperative pain management, rats received ketoprofen $(5 \mathrm{mg} / \mathrm{kg}$, subcutaneous injection daily) for 2 days. At 1-week time point the animals were humanely euthanized and the tissue implants were isolated for histology sectioning.

\title{
Statistical analysis
}

Significant differences between experimental groups were determined using independent two-tailed Students' t-test unless specified otherwise. In Figure 2f, one way ANOVA was used with Normality test (Shapiro-Wilk) and pairwise multiple comparison procedures (Holm-Sidak method). In Figure 4g, Kruskal-Wallis one way ANOVA on ranks was used and followed by pairwise multiple comparison procedures (Student-Newman-Keuls Method). In Figure 5z, two way repeated measures ANOVA was used with Normality test (Shapiro-Wilk) and followed by pairwise multiple comparison procedures (Holm-Sidak method). $\mathrm{p}<0.05$ was considered significant for all tests.

\section{Supplementary Material}

Refer to Web version on PubMed Central for supplementary material.

\section{ACKNOWLEDGEMENTS}

\begin{abstract}
We thank Kusha Marjan, and Patrick Lai from the University Health Network, Toronto, for their help on the optical mapping analysis. We thank Yang Liu from Osaka University, Japan, for her help on quantifying the platelet coverage on the AngioChip in the blood perfusion study. We thank Jason Wayne Miklas and Yun Xiao for their helpful discussion regarding human cardiomyocyte culture and cell seeding. We thank Aarash Sofla for his help with the POMaC synthesis. We thank Dr. Armand Keating and Iran Rashedi for providing us hMSCs and Yimu Zhao for her help in culturing and expanding hMSCs. We thank Dr. Jian Yang for suggestions regarding POMaC synthesis. This work was made possible by the National Sciences and Engineering Research Council of Canada (NSERC) Steacie Fellowship to M.R. This work was also funded by the Canadian Institutes of Health Research (CIHR) Operating Grant (MOP-126027), the Heart and Stoke Foundation GIA T6946, NSERC-CIHR Collaborative Health Research, Grant (CHRPJ 385981-10), NSERC Discovery Grant (RGPIN 326982-10), NSERC Discovery Accelerator Supplement (RGPAS 396125-10) and National Institutes of Health Grant 2R01 HL076485.
\end{abstract}

\section{REFERENCES}

1. Huh D, et al. Reconstituting organ-level lung functions on a chip. Science. 2010; 328:1662-1668. [PubMed: 20576885]

2. Kim HJ, Huh D, Hamilton G, Ingber DE. Human gut-on-a-chip inhabited by microbial flora that experiences intestinal peristalsis-like motions and flow. Lab on a Chip. 2012; 12:2165-2174. [PubMed: 22434367]

3. Kolesky DB, et al. 3D bioprinting of vascularized, heterogeneous cell-laden tissue constructs. Adv Mater. 2014; 26:3124-3130. doi:10.1002/adma.201305506. [PubMed: 24550124]

4. Zimmermann W-H, et al. Engineered heart tissue grafts improve systolic and diastolic function in infarcted rat hearts. Nature medicine. 2006; 12:452-458. doi:10.1038/nm1394.

5. Nunes SS, et al. Biowire: a platform for maturation of human pluripotent stem cell- derived cardiomyocytes. Nature methods. 2013; 10:781-787. [PubMed: 23793239]

6. Yang X, Pabon L, Murry CE. Engineering Adolescence Maturation of Human Pluripotent Stem Cell-Derived Cardiomyocytes. Circulation Research. 2014; 114:511-523. [PubMed: 24481842]

7. Bian W, Badie N, Himel IV HD, Bursac N. Robust T-tubulation and maturation of cardiomyocytes using tissue-engineered epicardial mimetics. Biomaterials. 2014; 35:3819-3828. [PubMed: 24508078] 
8. Takebe T, et al. Vascularized and functional human liver from an iPSC-derived organ bud transplant. Nature advance on. 2013 doi:10.1038/nature12271.

9. Thavandiran N, et al. Design and formulation of functional pluripotent stem cell-derived cardiac microtissues. Proceedings of the National Academy of Sciences. 2013 doi:10.1073/pnas. 1311120110.

10. Legant WR, et al. Microfabricated tissue gauges to measure and manipulate forces from 3D microtissues. Proceedings of the National Academy of Sciences of the United States of America. 2009; 106:10097-10102. doi:10.1073/pnas.0900174106. [PubMed: 19541627]

11. Bian W. Engineered skeletal muscle tissue networks with controllable architecture. Biomaterials. 2009; 30:1401-1412. [PubMed: 19070360]

12. Kim S, Lee H, Chung M, Jeon NL. Engineering of functional, perfusable 3D microvascular networks on a chip. Lab on a Chip. 2013 doi:10.1039/c3lc41320a.

13. Zheng Y, et al. In vitro microvessels for the study of angiogenesis and thrombosis. Proceedings of the National Academy of Sciences of the United States of America. 2012; 109:9342-9347. doi: 10.1073/pnas.1201240109. [PubMed: 22645376]

14. Zhang B, Peticone C, Murthy SK, Radisic M. A standalone perfusion platform for drug testing and target validation in micro-vessel networks. Biomicrofluidics. 2013; 7:044125.

15. Atala A, Kasper FK, Mikos AG. Engineering Complex Tissues. Science Translational Medicine. 2012; 4:160rv112-160rv112. doi:10.1126/scitranslmed.3004890.

16. Bae H, et al. Building Vascular Networks. Science Translational Medicine. 2012; 4:160ps123160ps123. doi:10.1126/scitranslmed.3003688.

17. Ye L, Zimmermann W-H, Garry DJ, Zhang J. Patching the Heart Cardiac Repair From Within and Outside. Circulation Research. 2013; 113:922-932. [PubMed: 24030022]

18. Baranski JD, et al. Geometric control of vascular networks to enhance engineered tissue integration and function. Proceedings of the National Academy of Sciences of the United States of America. 2013; 110:7586-7591. doi:10.1073/pnas.1217796110. [PubMed: 23610423]

19. Sekine $\mathrm{H}$, et al. In vitro fabrication of functional three-dimensional tissues with perfusable blood vessels. Nature Communications. 2013; 4:1399. doi:10.1038/ncomms2406.

20. Shandalov Y, et al. An engineered muscle flap for reconstruction of large soft tissue defects. Proceedings of the National Academy of Sciences. 2014:201402679.

21. Miller JS, et al. Rapid casting of patterned vascular networks for perfusable engineered threedimensional tissues. Nature Materials advance on. 2012 doi:10.1038/nmat3357.

22. Vollert I, et al. In-vitro perfusion of engineered heart tissue through endothelialized channels. Tissue Engineering. 2013

23. Tang MD, Golden AP, Tien J. Fabrication of collagen gels that contain patterned, micrometer-scale cavities. Adv. Mater. 2004; 16:1345. doi:10.1002/adma.200400766.

24. Ye X, et al. A biodegradable microvessel scaffold as a framework to enable vascular support of engineered tissues. Biomaterials. 2013

25. Bettinger CJJ, et al. Three-Dimensional Microfluidic Tissue-Engineering Scaffolds Using a Flexible Biodegradable Polymer. Advanced materials. 2006; 18:165-169. doi:10.1002/adma. 200500438. [PubMed: 19759845]

26. Bettinger CJ, et al. Silk Fibroin Microfluidic Devices. Advanced materials (Deerfield Beach, Fla.). 2007; 19:2847-2850. doi:10.1002/adma.200602487.

27. Tran RT, et al. Synthesis and characterization of a biodegradable elastomer featuring a dual crosslinking mechanism. Soft Matter. 2010; 6

28. Yang J, Webb AR, Ameer GA. Novel Citric Acid-Based Biodegradable Elastomers for Tissue Engineering. Adv. Mater. 2004; 16:511-516. doi:10.1002/adma.200306264.

29. Spiller K, Freytes D, Vunjak-Novakovic G. Macrophages Modulate Engineered Human Tissues for Enhanced Vascularization and Healing. Annals of Biomedical Engineering. 2014:1-12. doi: 10.1007/s10439-014-1156-8. [PubMed: 23918080]

30. Kibbe MR, et al. Citric acid-based elastomers provide a biocompatible interface for vascular grafts. Journal of Biomedical Materials Research Part A. 2010; 93A:314-324. doi:10.1002/jbm.a.32537. [PubMed: 19569210] 
31. Motlagh D, et al. Hemocompatibility evaluation of poly(diol citrate) in vitro for vascular tissue engineering. Journal of Biomedical Materials Research Part A. 2007; 82A:907-916. doi:10.1002/ jbm.a.31211. [PubMed: 17335023]

32. Dendukuri D, Pregibon DC, Collins J, Hatton TA, Doyle PS. Continuous- flow lithography for high-throughput microparticle synthesis. Nature Materials. 2006; 5:365-369. [PubMed: 16604080]

33. Derby B. Printing and prototyping of tissues and scaffolds. Science (New York, N.Y.). 2012; 338:921-926. doi:10.1126/science.1226340.

34. Hoshi RA. Nanoporous Biodegradable Elastomers. Adv. Mater. 2009; 21:188-192.

35. Nagueh SF, et al. Altered titin expression, myocardial stiffness, and left ventricular function in patients with dilated cardiomyopathy. Circulation. 2004; 110:155-162. doi:10.1161/01.CIR. 0000135591.37759.AF. [PubMed: 15238456]

36. Weis SM, et al. Myocardial mechanics and collagen structure in the osteogenesis imperfecta murine (oim). Circ Res. 2000; 87:663-669. [PubMed: 11029401]

37. Coirault $\mathrm{C}$, et al. Increased compliance in diaphragm muscle of the cardiomyopathic Syrian hamster. Journal of applied physiology. 1998; 85:1762-1769. [PubMed: 9804579]

38. Omens JH. Stress and strain as regulators of myocardial growth. Progress in biophysics and molecular biology. 1998; 69:559-572. [PubMed: 9785956]

39. Yeh WC, et al. Elastic modulus measurements of human liver and correlation with pathology. Ultrasound in medicine \& biology. 2002; 28:467-474. [PubMed: 12049960]

40. Merkel TC, Bondar VI, Nagai K, Freeman BD, Pinnau I. Gas sorption, diffusion, and permeation in poly(dimethylsiloxane). Journal of Polymer Science Part B: Polymer Physics. 2000; 38:415434. doi:10.1002/(sici)1099- 0488(20000201)38:3<415::aid-polb8>3.0.co;2-z.

41. Toepke MW, Beebe DJ. PDMS absorption of small molecules and consequences in microfluidic applications. Lab Chip. 2006; 6:1484-1486. [PubMed: 17203151]

42. Gaillard PJ, et al. Establishment and functional characterization of an in vitro model of the bloodbrain barrier, comprising a co-culture of brain capillary endothelial cells and astrocytes. Eur J Pharm Sci. 2001; 12:215-222. [PubMed: 11113640]

43. Yuan W, Lv Y, Zeng M, Fu BM. Non-invasive measurement of solute permeability in cerebral microvessels of the rat. Microvascular research. 2009; 77:166-173. [PubMed: 18838082]

44. Adamson RH, Huxley VH, Curry FE. Single capillary permeability to proteins having similar size but different charge. 254(1988)

45. Woosley RL, Chen Y, Freiman JP, Gillis RA. MEchanism of the cardiotoxic actions of terfenadine. JAMA. 1993; 269:1532-1536. doi:10.1001/jama.1993.03500120070028. [PubMed: 8445816]

46. Ogawa $\mathrm{S}$, et al. Three-dimensional culture and cAMP signaling promote the maturation of human pluripotent stem cell-derived hepatocytes. Development. 2013; 140:3285-3296. doi:10.1242/dev. 090266. [PubMed: 23861064]

47. Boudou T, et al. A microfabricated platform to measure and manipulate the mechanics of engineered cardiac microtissues. Tissue Eng Part A. 2012; 18:910-919. [PubMed: 22092279]

48. Radisic M, et al. Functional assembly of engineered myocardium by electrical stimulation of cardiac myocytes cultured on scaffolds. Proceedings of the National Academy of Sciences. 2004; 101:18129-18134.

49. Tulloch NL, et al. Growth of engineered human myocardium with mechanical loading and vascular coculture. Circulation Research. 2011; 109:47-59. [PubMed: 21597009]

50. Wu W, Allen RA, Wang Y. Fast-degrading elastomer enables rapid remodeling of a cell-free synthetic graft into a neoartery. Nature medicine. 2012; 18:1148-1153. doi:10.1038/nm.2821.

51. Bhatia S, Balis U, Yarmush M, Toner M. Effect of cell-cell interactions in preservation of cellular phenotype: cocultivation of hepatocytes and nonparenchymal cells. The FASEB Journal. 1999; 13:1883-1900. [PubMed: 10544172]

52. Mazza E, Ehret AE. Mechanical biocompatibility of highly deformable biomedical materials. Journal of the mechanical behavior of biomedical materials. 2015; 48:100-124. doi:10.1016/ j.jmbbm.2015.03.023. [PubMed: 25916818]

53. Engelmayr GC, et al. Accordion-like honeycombs for tissue engineering of cardiac anisotropy. Nature Materials. 2008; 7:1003-1010. doi:10.1038/nmat2316. [PubMed: 18978786] 
54. Nava A, Mazza E, Furrer M, Villiger P, Reinhart W. In vivo mechanical characterization of human liver. Medical image analysis. 2008; 12:203-216. [PubMed: 18171633]

55. Hoshi RA, et al. The blood and vascular cell compatibility of heparin-modified ePTFE vascular grafts. Biomaterials. 2013; 34:30-41. doi:10.1016/j.biomaterials.2012.09.046. [PubMed: 23069711]

56. Sefton, MV.; Gemmell, CH.; Gorbet, MB. Biomaterials Science. Third Edition. Ratner, Buddy D.; Hoffman, Allan S.; Schoen, Frederick J.; Lemons, Jack E., editors. Academic Press; 2013. p. 758-760.

57. Zhang B, Green JV, Murthy SK, Radisic M. Label-free enrichment of functional cardiomyocytes using microfluidic deterministic lateral flow displacement. PloS one. 2012; 7:e37619. [PubMed: 22666372]

58. Berry M, Friend D. High-yield preparation of isolated rat liver parenchymal cells A biochemical and fine structural study. The Journal of cell biology. 1969; 43:506-520. [PubMed: 4900611]

59. Kennedy M, D'Souza SL, Lynch-Kattman M, Schwantz S, Keller G. Development of the hemangioblast defines the onset of hematopoiesis in human ES cell differentiation cultures. Blood. 2007; 109:2679-2687. [PubMed: 17148580]

60. Lian X, et al. Directed cardiomyocyte differentiation from human pluripotent stem cells by modulating Wnt/ $/$-catenin signaling under fully defined conditions. Nature protocols. 2013; 8:162-175. [PubMed: 23257984]

61. Zeebregts C, Heijmen R, Van Den Dungen J, Van Schilfgaarde R. Non - suture methods of vascular anastomosis. British journal of surgery. 2003; 90:261-271. [PubMed: 12594661] 
a

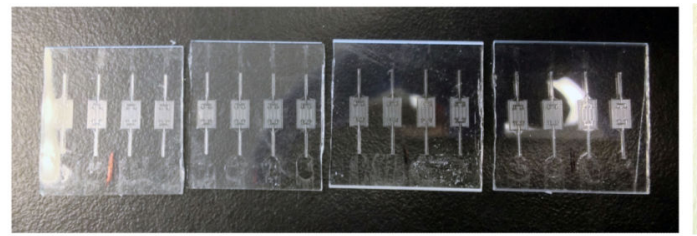

C

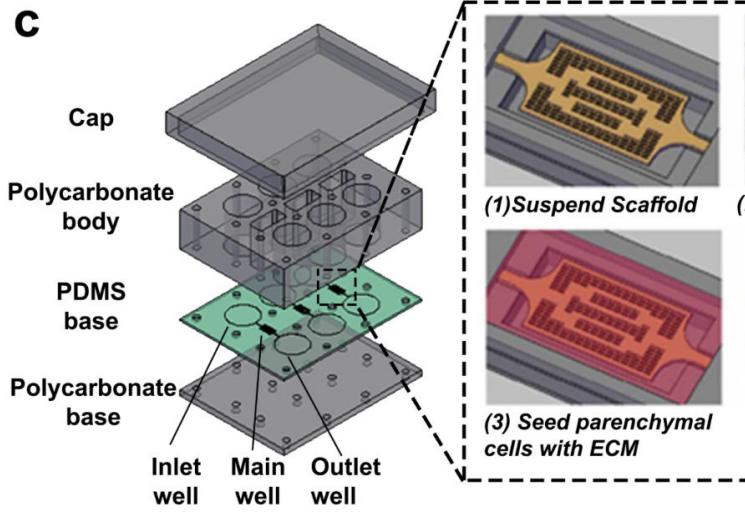

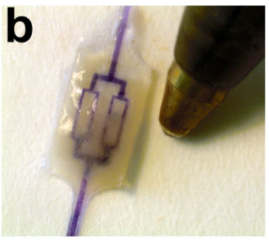

d Parenchymal cells
(Parenchymal space)

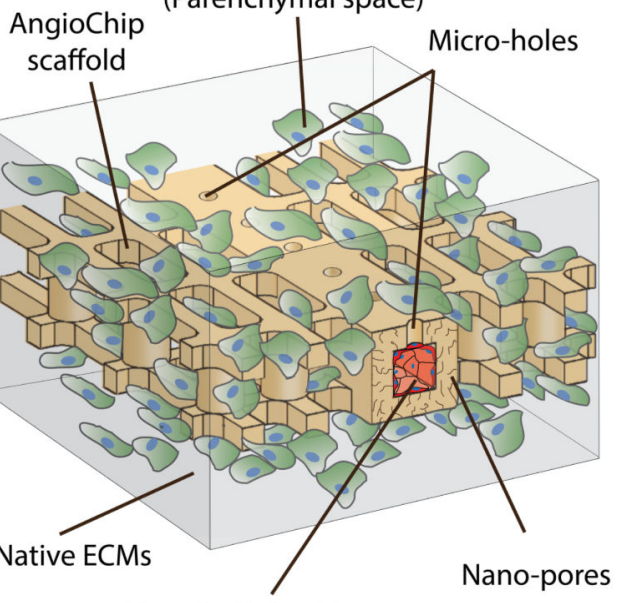

Endothelialized lumen
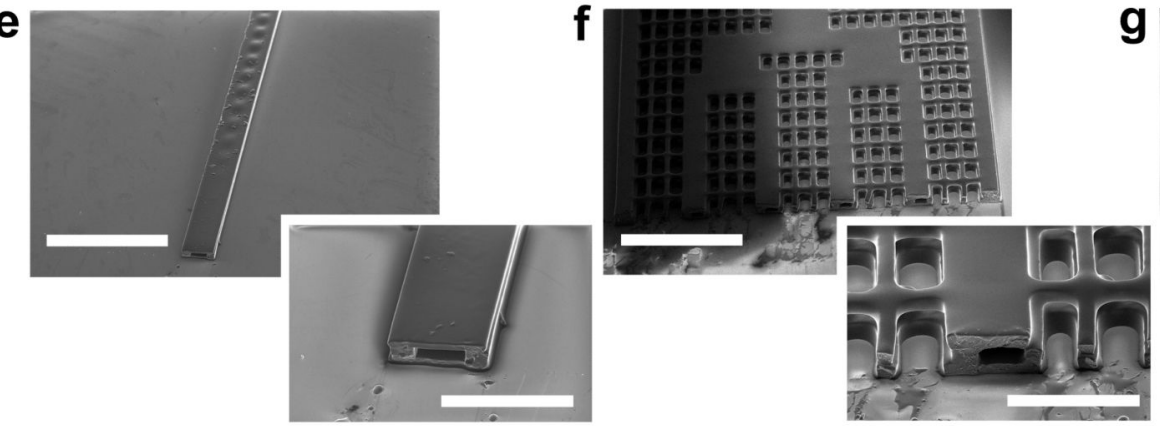

g

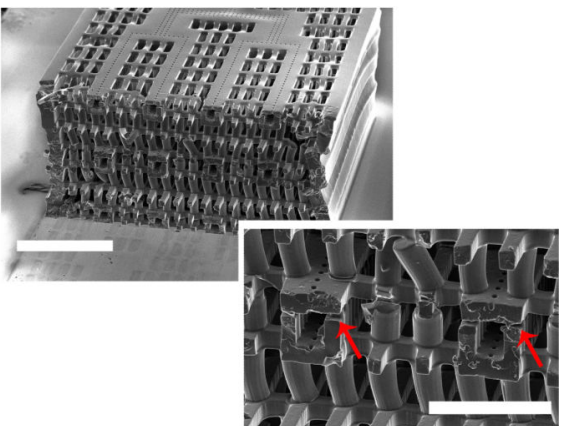

h

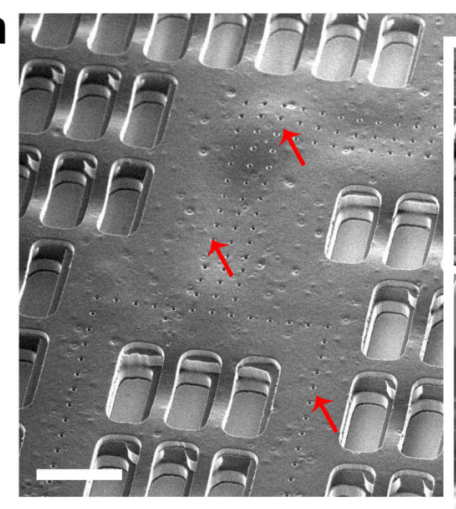

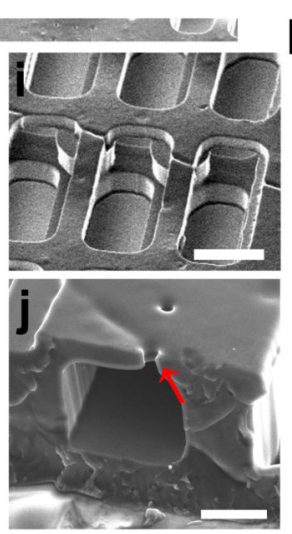

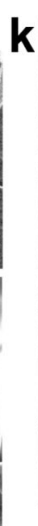

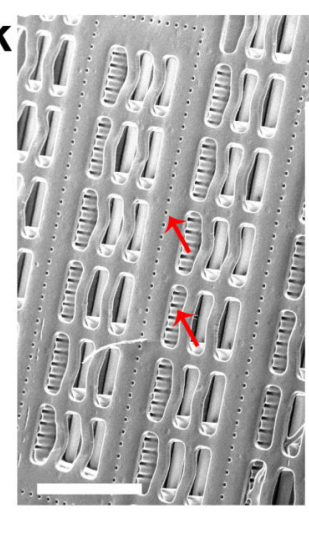

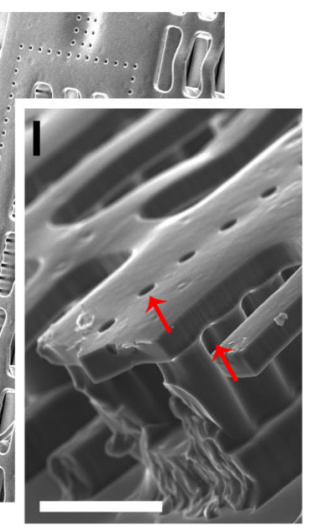

m

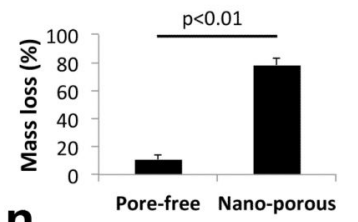

Figure 1. AngioChip scaffold fabrication and visualization

a, Image of multiple AngioChip scaffolds patterned in parallel on glass slides. $\mathbf{b}$, Image of an AngioChip hepatic tissue, perfused with a color dye, beside the tip of a ballpoint pen for scale. c, Schematic of the assembly of the bioreactor and the assembly of vascularized tissue. d, Schematic of a part of an AngioChip tissue. e-g, SEM of (e) a 1-D tube (scale bar: $1.5 \mathrm{~mm}$ and $500 \mu \mathrm{m}$ ), (f) a 2-D AngioChip scaffold (scale bar: $1 \mathrm{~mm}$ and $300 \mu \mathrm{m}$ ) and (g) a multi-layer 3-D AngioChip scaffold with $20 \mu \mathrm{m}$ micro-holes (scale bar: $1 \mathrm{~mm}$ and $400 \mu \mathrm{m}$ ) created using the 3-D stamping technique. h, SEM of an AngioChip scaffold with 10 $\mu \mathrm{m}$ 
micro-holes on the channel walls. Scale bar: $200 \mu \mathrm{m}$. SEM of (i) the 3-D lattice matrix in between the micro-channels (scale bar: $100 \mu \mathrm{m}$ ) and (j) the cross-section of a $10 \mu \mathrm{m}$ microhole on the channel wall (scale bar: $50 \mu \mathrm{m}$ ). Red arrows point to the micro-holes. k-l, SEM of the AngioChip scaffolds with $20 \mu \mathrm{m}$ micro-holes on the top and side walls of the microchannels. Red arrows point to the micro-holes on the top and side walls. Scale bar: (k) $400 \mu \mathrm{m}$, and (1) $100 \mu \mathrm{m}$. m, Mass loss in 1 day from porogen leaching for pore-free and nanoporous AngioChip scaffolds (average \pm s.d., $n=3$ ). Pore-free and nano-porous corresponds to scaffolds fabricated without or with the use of porogen, respectively. $\mathbf{n}$, SEM of the surface of AngioChip scaffold after porogen leaching. Scale bar: 500nm. 
a
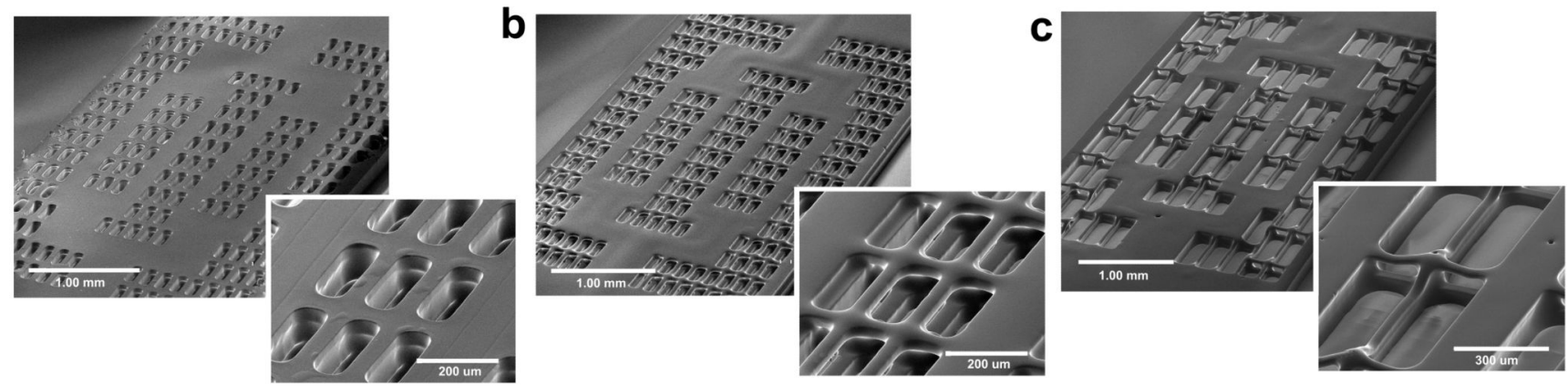

d
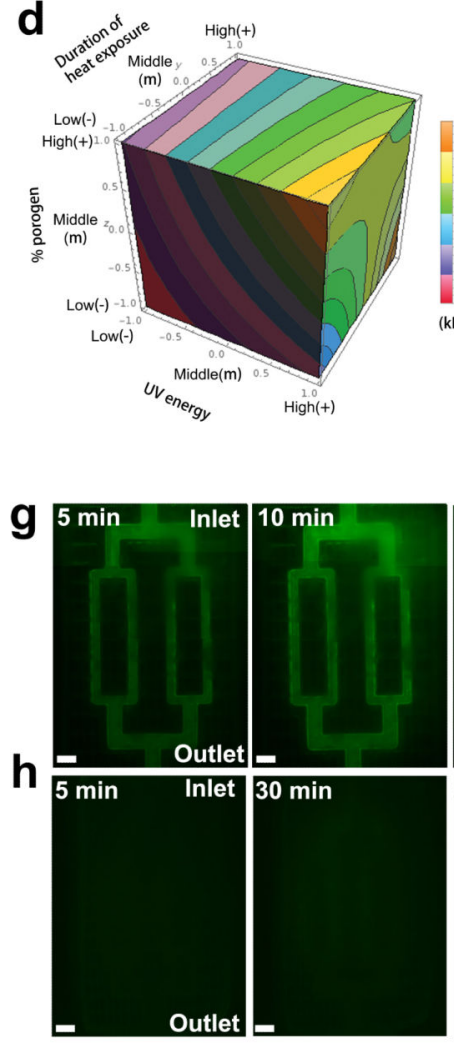

e

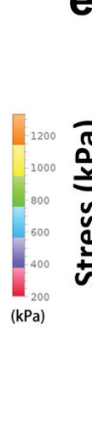

$80-\cdots$ Design A(LD) —Design A(SD)

$70-\cdots$ Design $B(L D)$ Design $B(S D)$

$70-\cdots$ Design $\mathrm{C}(\mathrm{LD})$

Figure 2. Physical characterization of the AngioChip scaffolds

a-c, SEM of the AngioChip scaffolds with lattice matrix of increasing macro-porosity: (a) design A (scale bar: $1 \mathrm{~mm}$ and $200 \mu \mathrm{m}$ ), (b) design B (scale bar: $1 \mathrm{~mm}$ and $200 \mu \mathrm{m}$ ), and (c) design $\mathrm{C}$ (scale bar: $1 \mathrm{~mm}$ and $300 \mu \mathrm{m}$ ). d, Isosurface plot of the bulk elasticity of POMaC as a function of UV energy, heat exposure duration and percent of porogen, evaluated at the citric acid to maleic anhydride monomer molar ratio of 1:4. e, Representative uniaxial tensile stress-strain plots of the AngioChip scaffolds with the three different lattice matrix designs. Long-edge direction (LD) and short-edge direction (SD) correspond to the circumferential and longitudinal axes of the heart, respectively $(n=3)$. $\mathbf{f}$, Permeability of AngioChip scaffold wall to FITC-dextran $(70 \mathrm{kDa})$ with and without ECs coating or $10 \mu \mathrm{m}$ micro-holes. (average \pm s.d, n=3). g, Time-lapse fluorescent images of 332Da FITC diffusing from the built-in network of an AngioChip scaffold with $10 \mu \mathrm{m}$ micro-holes to the surrounding lattice matrix. Scale bar: $300 \mu \mathrm{m}$. Final Images were stitched from multiple images. h, Time-lapse images 
of carboxyfluorescein diacetate (CFDA, 557Da) diffusing from the built-in internal network with $10 \mu \mathrm{m}$ micro-holes to the surrounding cardiac tissue where it is cleaved by the viable cells $(n=3)$. Scale bar: $300 \mu \mathrm{m}$. i, Burst pressure of AngioChip scaffolds (average \pm s.d., $n=4$ ) and rat femoral veins (average \pm s.d., $\mathrm{n}=6$ ). 

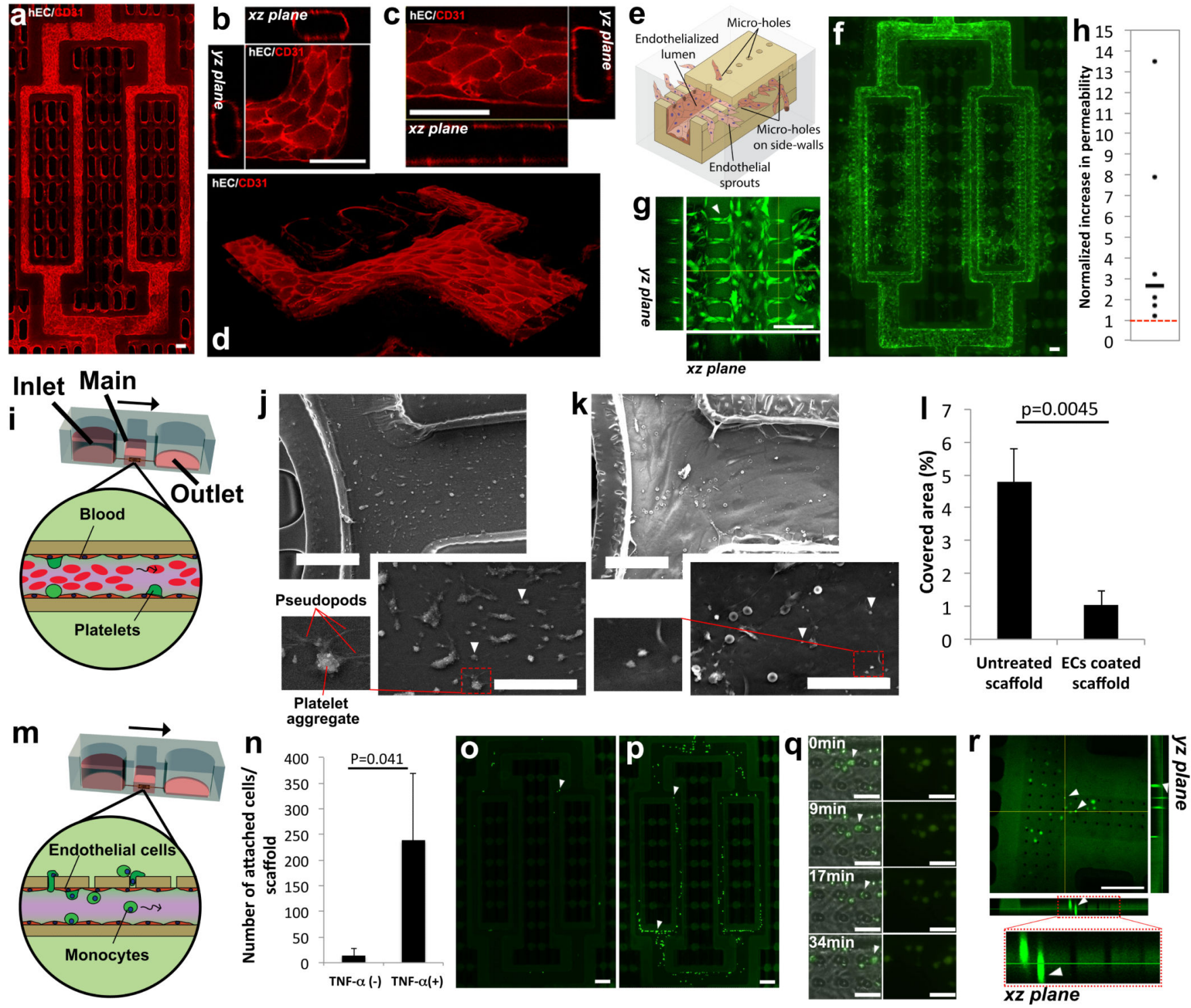

Figure 3. Endothelialization of the AngioChip network

a-d, Immunostaining (CD31, red) of the internal vasculature of an Angiochip scaffold on

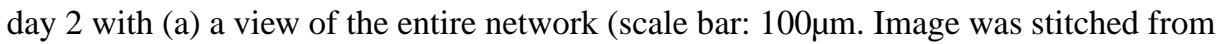

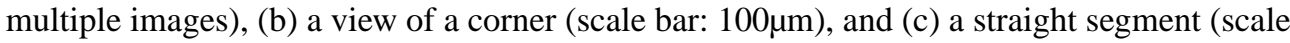
bar: $100 \mu \mathrm{m})$, and $(\mathrm{d})$ a branch $(\mathrm{n}=3)$. e, Schematics of ECs migrating and sprouting from the inner lumen of the micro-channel to the surrounding parenchyma through the built-in $20 \mu \mathrm{m}$ micro-holes on the side-walls. f-g, Fluorescent image of ECs (labeled green) sprouting from the channel networks into the parenchymal space on day $2(n=4)$. White arrow points to a vessel sprouting within the micro-hole on the sidewall. Scale bar: $100 \mu \mathrm{m}$. $\mathbf{h}$, Change in permeability of the endothelialized networks with $20 \mu \mathrm{m}$ micro-holes to $70 \mathrm{kDa}$ dextran upon treatment with thymosin $\beta 4$ for $24 \mathrm{hr}$. Normalization was performed by dividing the permeability of the endothelium after T $\beta 4$ application for $24 \mathrm{hr}$ to the unstimulated starting endothelium permeability of the same batch $(n=6)$. $\mathbf{i}$, Schematics of the human whole blood perfusion through the endothelialized AngioChip network. The AngioChip scaffold is 
located in the main well. The black arrow indicates the flow direction. $\mathbf{j}-\mathbf{k}$, SEM of (j) the luminal surface of an untreated scaffold network and (k) the luminal surface of an endothelialized network (day 2 in culture) after perfusion with $1 \%(\mathrm{v} / \mathrm{v})$ heparinized human whole blood at 15 dynes $/ \mathrm{cm}^{2}$ for $30 \mathrm{~min}(\mathrm{n}=3)$. Scale bar: (j, k) $100 \mu \mathrm{m}$, and (inset) $50 \mu \mathrm{m}$.

White arrows point to representative platelets. I, Quantification of the luminal surface area of the scaffold network covered by the platelets (average \pm s.d., $n=3$ ). $\mathbf{m}$, Schematic of the perfusion of monocytes through the endothelialized network with $10 \mu \mathrm{m}$ micro-holes. $\mathbf{n}$, Quantification of adhered THP-1 monocytes on the inner luminal surface of ECs coated AngioChip scaffold (day 2 in culture) with or without TNF-a treatment. (average $\pm s . d, n=3$ ). o-p, Images of fluorescently labeled THP-1 monocytes on ECs coated AngioChip network (o) without or (p) with prior TNF-a treatment $(n=3)$. Scale bar: $200 \mu \mathrm{m}$. White arrows point to adhered monocytes. q, Time-lapse images of fluorescently labeled monocytes (green) migrating laterally in the endothelialized scaffold network passing through a $10 \mu \mathrm{m}$ microhole $(n=3)$. Scale bar: $50 \mu \mathrm{m}$. $\mathbf{r}$, Trans-endothelial migration of fluorescently labeled monocytes (green) through the $10 \mu \mathrm{m}$ micro-holes on the channel wall $(n=3)$. Scale bar: $200 \mu \mathrm{m}$. White arrows point to migrating monocytes. 

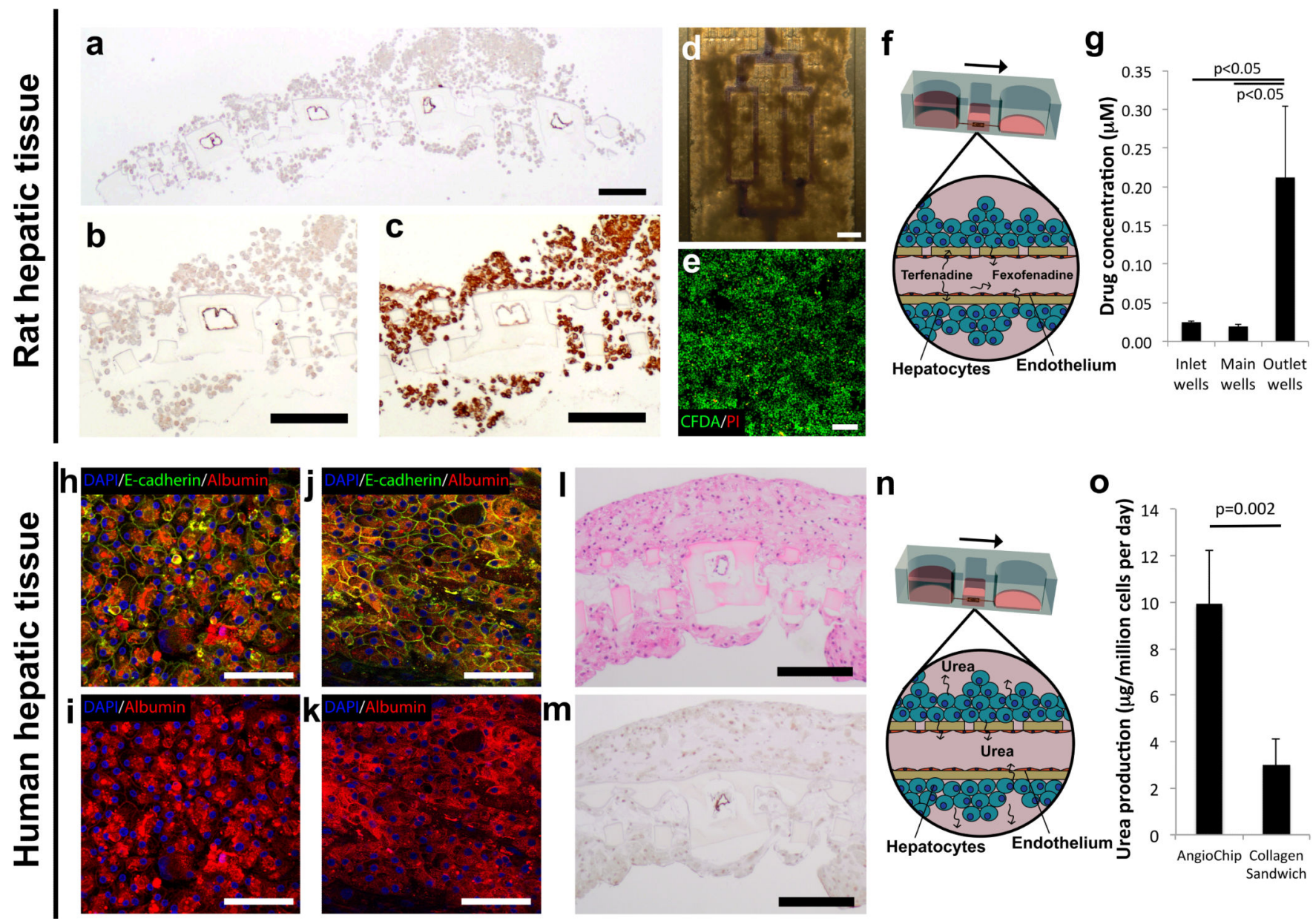

$\mathbf{n}$

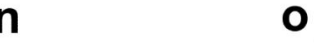

Figure 4. Vascularized hepatic tissue assembly

a-c, Histology cross-section of a hepatic tissue with $10 \mu \mathrm{m}$ micro-holes on day 6 stained for (a-b) CD31 to identify endothelial cells ( $n=3$, scale bar: $200 \mu \mathrm{m}$ ) and (c) albumin to identify hepatocytes ( $\mathrm{n}=3$, scale bar: $200 \mu \mathrm{m})$. d, Bright-field image of a hepatic tissue perfused with

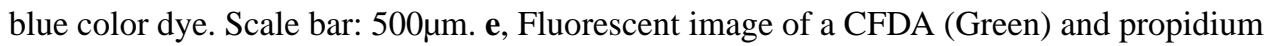
iodide (PI, red) stained hepatic tissue shows a high cell viability. Scale bar: $200 \mu \mathrm{m} \mathbf{f}$,

Schematic of terfenadine diffusing through the vessel wall with $10 \mu \mathrm{m}$ micro-holes into the hepatic tissue and then subsequently being converted into fexofenadine and released back into the vasculature. g, Concentration of fexofenadine in the bioreactor inlet, main, and outlet wells after $24 \mathrm{hr}$ perfusion of terfenadine at $10 \mu \mathrm{M}$ from inlet wells (average \pm s.e.m., $\mathrm{n}=4$ ) on day 6 . h-k, Immunostaining of E-cadherin and albumin on (h-i) human hepatocyte monolayer collagen sandwich and ( $\mathrm{j}-\mathrm{k})$ human AngioChip hepatic tissue on day $7(\mathrm{n}=3)$. Scale bar: $100 \mu \mathrm{m}$. I-m, Histology cross-sections of human AngioChip hepatic tissues with 10 $\mu \mathrm{m}$ micro-holes on day 7 stained with (l) Hematoxylin and Eosin (H\&E), and (m) CD31 to identify endothelial cells $(n=3)$. Scale bar: $200 \mu \mathrm{m}$. $\mathbf{n}$, Schematic of urea secretion from the hepatic tissue and released into the vasculature with $10 \mu \mathrm{m}$ micro-holes. o, Quantification of urea secretion, normalized to cell number, into the bioreactor main well and outlet well from AngioChip hepatic tissue and collagen sandwich control on day 3 (average \pm s.d., $n=4$ ). 


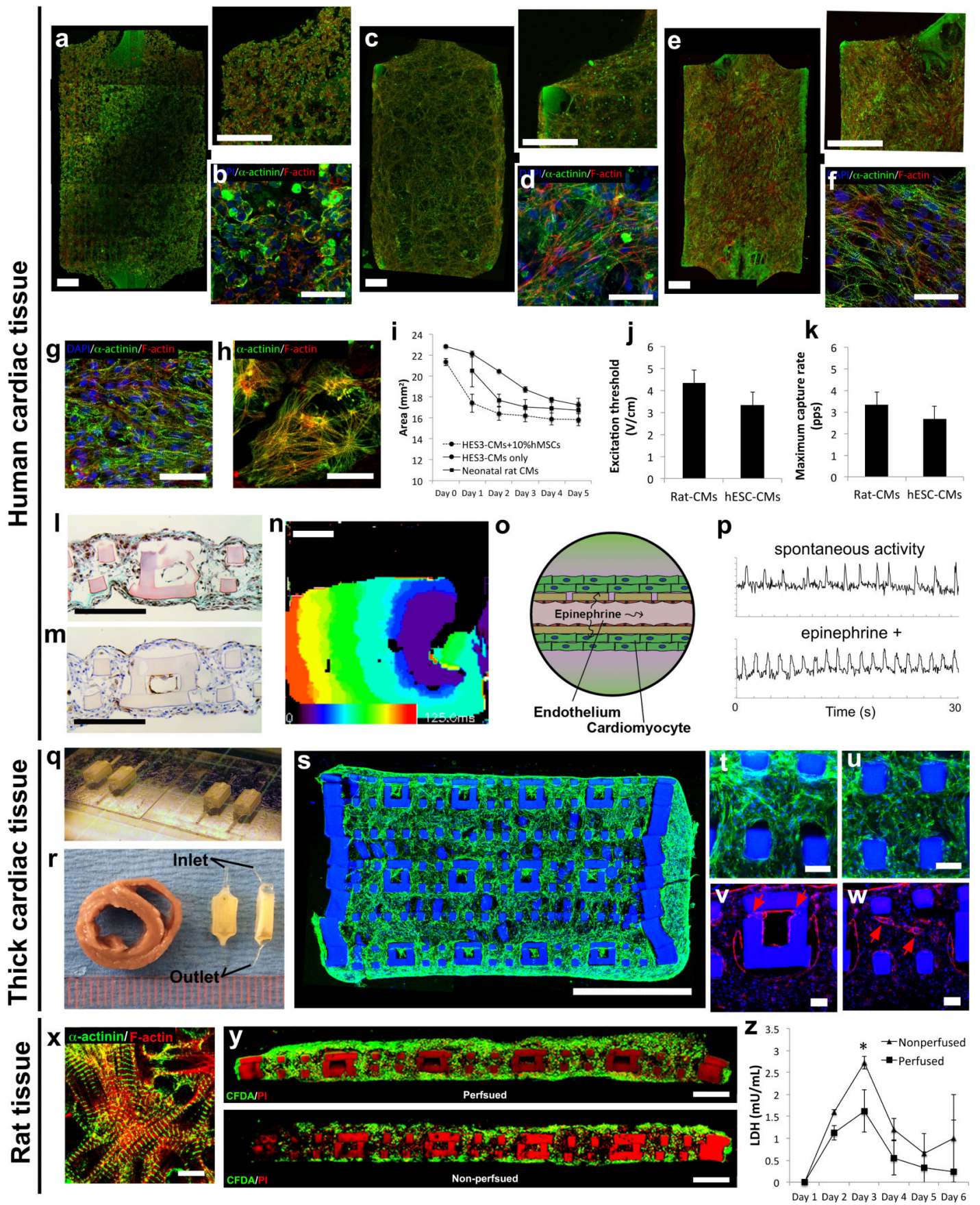

Figure 5. Vascularized cardiac tissue assembly

a-f, Immunostaining of sarcomeric-a-actinin (green) and F-actin (red) on human AngioChip cardiac tissues $(\mathrm{a}, \mathrm{b})$ with $10 \%$ hMSCs on day 1 and $(\mathrm{e}, \mathrm{f})$ day 7 or $(\mathrm{c}, \mathrm{d})$ without hMSCs on day $7(n=3)$. Scale bar: $(a, c, e) 500 \mu m$, and $(b, d, f) 50 \mu m$. (a,c,e) Final images were stitched from multiple images. g-h, Immunostaining of sarcomeric-a-actinin (green) and F-actin (red) on $(\mathrm{g})$ biowire platform and $(\mathrm{h})$ monolayer $(\mathrm{n}=3)$ on day 7. Scale bar: $50 \mu \mathrm{m}$. $\mathbf{i}$,

Quantification of decreasing tissue size due to cell remodelling for neonatal rat cardiomyocytes (rat-CMs), human embryonic stem cell derived cardiomyocytes (hESC- 
CMs), and hESC-CMs mixed with 10\% human meshenchymal stem cells (hMSCs). (average \pm s.d., $n=3$ ). $\mathbf{j}-\mathbf{k}$, Electrical excitability parameters (average \pm s.d., $n=3$ ) on day 7. l-m, Histology cross-sections of human cardiac tissues on day 7 stained with (l) Masson's Trichrome, and (m) CD31 to identify endothelial cells $(\mathrm{n}=3)$. Scale bar: $200 \mu \mathrm{m}$. $\mathbf{n}$, Activation map of human AngioChip cardiac tissue on day 7 (n=7). Scale bar, $1 \mathrm{~mm}$. Activation of the construct is seen from stimulus point on the right propagating to the left over a time span of $100 \mathrm{~ms}$, in a uniform manner. $\mathbf{o}$, Schematic of perfusion delivery of epinephrine drug through the built-in vasculature with $10 \mu \mathrm{m}$ micro-holes. p, Initial spontaneous contraction trace and drug stimulated contraction trace of a human cardiac tissue on day 7 perfused with $10 \mu \mathrm{M}$ epinephrine ( $\mathrm{n}=3$ ). $\mathbf{q}$, Image of multiple thick AngioChip scaffolds patterned in parallel on glass slides. $\mathbf{r}$, Image of two thick AngioChip cardiac tissues placed face-up and side-up beside a slice of an adult rat heart. Scale shown in mm. s-u, Immunostaining of (s-u) F-actin (green) of the cross-section of an endothelialized

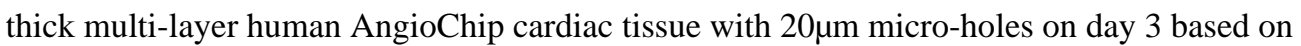
fibrin gel and hESC-derived CMs (n=3). (s) Final image was stitched from multiple images. High magnification images of tissue fibers in the parenchymal space near $(t)$ the edge region and (u) the center region. Scale bar: (s) $1 \mathrm{~mm}$, and (t,u) $50 \mu \mathrm{m}$. v-w, Immunostaining of CD31 of (v) an endothelialized micro-channel lumen with $20 \mu \mathrm{m}$ micro-holes that guide sprouting (red arrows) and (w) an adjacent parenchymal space with self-assembled microvasculature (red arrows) in a thick multi-layer human AngioChip cardiac tissue on day $3(\mathrm{n}=3)$. Scale bar: $(\mathrm{v}, \mathrm{w}) 50 \mu \mathrm{m}$. x, Immunostaining of sarcomeric-a-actinin (green) and F-actin (red) on a rat AngioChip cardiac tissue on day 7. Scale bar: 10 $\mu \mathrm{m}$. y, CFDA (green) and PI (red) stained images of the cross-section of rat cardiac tissues with $10 \mu \mathrm{m}$ micro-holes cultivated with or without medium perfusion on day $7(n=3)$. Scaffold also stains red. Scale bar: $200 \mu \mathrm{m}$. Final images were stitched from multiple images. z, Quantification of lactate dehydrogenase (LDH) secretion from rat cardiac tissues cultivated with or without medium perfusion (average \pm s.d., $\mathrm{n}=4$ ). *, significant difference between groups with $\mathrm{p}<0.05$. 

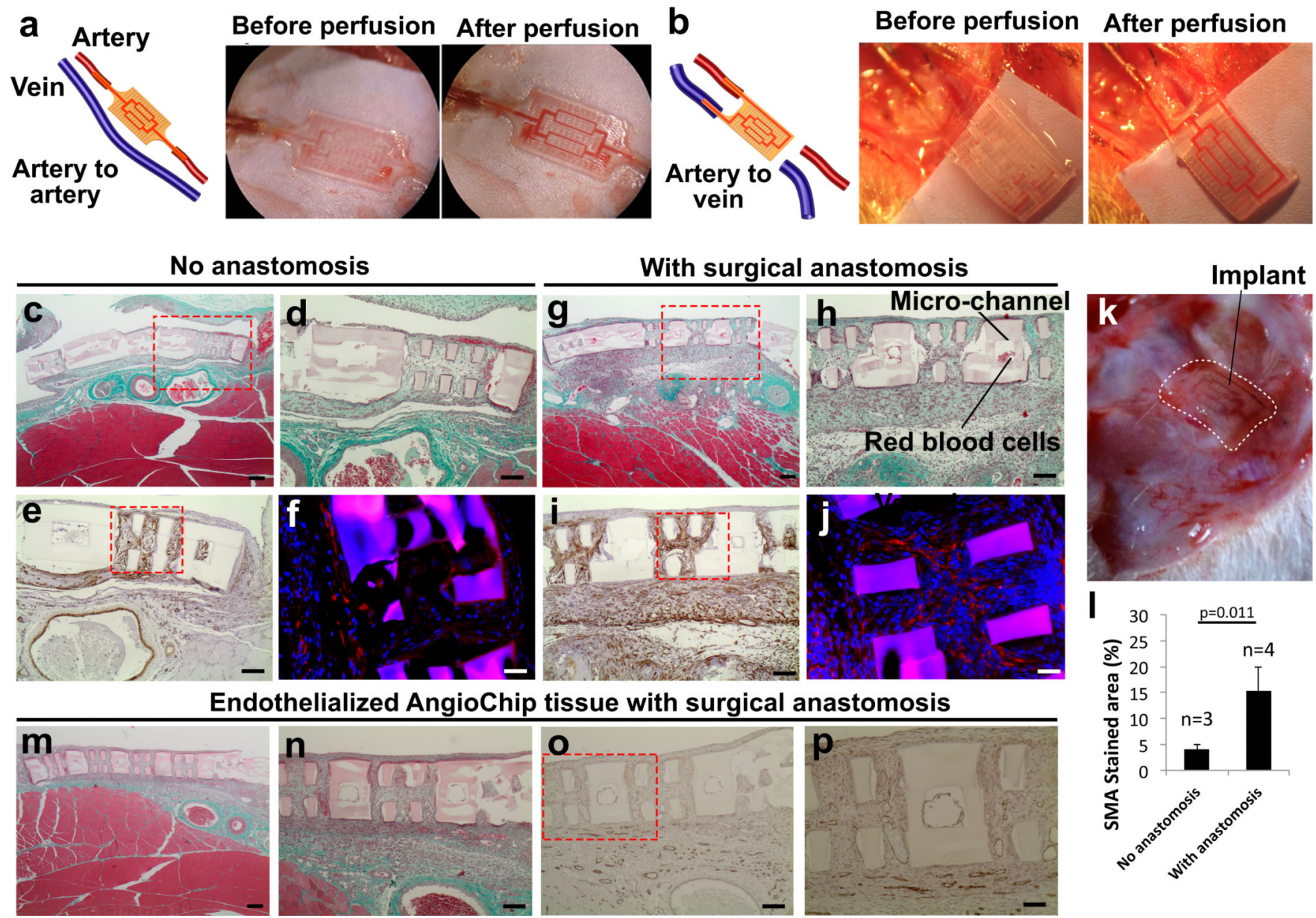

Figure 6. Surgical anastomosis of the cardiac tissue

a-b, Surgical anastomosis of the AngioChip cardiac tissue on the rat femoral vessels in the configuration of (a) artery-to-artery graft and (b) artery-to-vein graft. Blood perfusion was established immediately after anastomosis. Papers were placed under the implants during imaging for better visual contrast. $\mathbf{c}-\mathbf{j}$, Cross-section of the non-endothelialized rat cardiac tissue implants, 1 week after surgery $(c-f)$ without $(n=3)$ or $(g-j)$ with direct anastomosis $(\mathrm{n}=4)$ in the configuration of artery-to-vein graft. The sections were stained with (c-d, g-h) Masson's Trichrome, (e,i) smooth muscle actin, and (f-j) troponin T (red). Scale bar: (c,g) $200 \mu \mathrm{m}$ and (d-e, h-i) $100 \mu \mathrm{m}$, and (f,j) $50 \mu \mathrm{m}$. k, Image of a cardiac tissue implant on rat hindlimb 1 week after surgery with direct anastomosis in the configuration of artery-to-vein graft. White dotted line outlines the AngioChip implant. 1, Quantification of area stained by smooth muscle actin (average \pm s.d.).m-p, Histology cross-sections of an AngioChip cardiac tissue endothelialized with Lewis rat primary vein endothelial cells and implanted with direct surgical anastomosis after 1 week $(n=3)$. The sections were stained with $(m-n)$

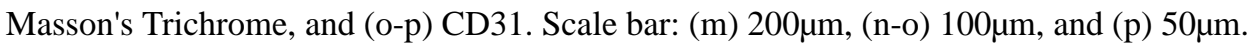

